\title{
Human pallidothalamic and cerebellothalamic tracts: anatomical basis for functional stereotactic neurosurgery
}

\author{
Marc N. Gallay · Daniel Jeanmonod • \\ Jian Liu · Anne Morel
}

Received: 7 September 2007 / Accepted: 20 December 2007/Published online: 10 January 2008

(C) The Author(s) 2008

\begin{abstract}
Anatomical knowledge of the structures to be targeted and of the circuitry involved is crucial in stereotactic functional neurosurgery. The present study was undertaken in the context of surgical treatment of motor disorders such as essential tremor (ET) and Parkinson's disease (PD) to precisely determine the course and threedimensional stereotactic localisation of the cerebellothalamic and pallidothalamic tracts in the human brain. The course of the fibre tracts to the thalamus was traced in the subthalamic region using multiple staining procedures and their entrance into the thalamus determined according to our atlas of the human thalamus and basal ganglia [Morel (2007) Stereotactic atlas of the human thalamus and basal ganglia. Informa Healthcare Inc., New York]. Stereotactic three-dimensional coordinates were determined by sectioning thalamic and basal ganglia blocks parallel to stereotactic planes and, in two cases, by correlation with magnetic resonance images (MRI) from the same brains prior to sectioning. The major contributions of this study are to provide: (1) evidence that the bulks of the cerebellothalamic and pallidothalamic tracts are clearly separated up to their thalamic entrance, (2) stereotactic maps of the
\end{abstract}

M. N. Gallay · D. Jeanmonod · J. Liu · A. Morel $(\bowtie)$

Laboratory for Functional Neurosurgery, Neurosurgery Clinic,

University Hospital Zürich,

Sternwartstrasse 6, 8091 Zurich, Switzerland

e-mail: anne.morel@usz.ch

Present Address:

J. Liu

Department of Physiology and Pathophysiology,

School of Medicine, Xi'an Jiaotong University, 710061 Xian,

People's Republic of China two tracts in the subthalamic region, (3) the possibility to discriminate between different subthalamic fibre tracts on the basis of immunohistochemical stainings, (4) correlations of histologically identified fibre tracts with highresolution MRI, and (5) evaluation of the interindividual variability of the fibre systems in the subthalamic region. This study should provide an important basis for accurate stereotactic neurosurgical targeting of the subthalamic region in motor disorders such as $\mathrm{PD}$ and $\mathrm{ET}$.

Keywords Basal ganglia - Thalamus - Motor disorders Essential tremor · Parkinson's disease

$\begin{array}{ll}\text { Abbreviations } & \\ a c & \text { Anterior commissure } \\ a l & \text { Ansa lenticularis } \\ \text { Acb } & \text { Accumbens nucleus } \\ \text { AChE } & \text { Acethylcholinesterase } \\ \text { Amg } & \text { Amygdala } \\ a p & \text { Ansa peduncularis } \\ \mathrm{AV} & \text { Anteroventral nucleus } \\ \mathrm{B} & \text { Basal nucleus of Meynert } \\ b i c & \text { Brachium of the inferior colliculus } \\ \mathrm{CaBP} & \text { Calcium-binding proteins } \\ \mathrm{Cd} & \text { Caudate nucleus } \\ \mathrm{CeM} & \text { Central medial nucleus } \\ \mathrm{CB} & \text { Calbindin D-28K } \\ \mathrm{CR} & \text { Calretinin } \\ \mathrm{CL} & \text { Central lateral nucleus } \\ \mathrm{Cl} & \text { Claustrum } \\ \mathrm{CM} & \text { Centre médian nucleus } \\ \mathrm{CTT} & \text { (or centromedian) } \\ f c t & \text { Cerebellothalamic tractotomy } \\ & \text { Fasciculus cerebello-thalamicus }\end{array}$




$\begin{array}{lll}f l & \text { Fasciculus lenticularis } & \text { VLp }(\mathrm{d}, \mathrm{v}, \mathrm{pl}) \\ f r f & \\ f t & \text { Fasciculus retroflexus } & \text { VM } \\ f x & \text { Fasciculus thalamicus } & \text { VPI } \\ \mathrm{GPi} & \text { Fornix } & \text { VPL }(\mathrm{p}) \\ \mathrm{GPe} & \text { Globus pallidus, internal segment } & \\ \mathrm{Hip} & \text { Globus pallidus, external segment } & \text { VPM } \\ \mathrm{Hyp} & \text { Hippocampus } & \text { VPMpc } \\ i c & \text { Hypothalamus } & \\ \mathrm{IC} & \text { Internal capsule } & \text { ZI } \\ i m l & \text { Inferior colliculus } & \\ \text { LD } & \text { Internal medullary lamina } & \\ \text { LGN } & \text { Lateral dorsal nucleus } & \\ \mathrm{Li} & \text { Lateral geniculate nucleus } & \end{array}$

Ventral lateral posterior nucleus (dorsal, ventral, and paralamellar divisions)

Ventral medial nucleus

Ventral posterior inferior nucleus

Ventral posterior lateral nucleus (posterior division)

Ventral posterior medial nucleus

Ventral posterior medial nucleus, parvocellular division

Zona incerta

\section{Introduction}

LP

M1

MB

$\mathrm{MD}(\mathrm{pc}, \mathrm{mc}, \mathrm{pl})$

MGN

$m l$

$m t t$

MV

ot

PAG

$p c$

Pf

PF

$\mathrm{PMc}$

$\mathrm{PMr}$

Po

pre-SMA

PTT

PuA

PuM

PuT

PV

$\mathrm{R}$

RN

$\mathrm{SC}$

SG

sm

SMA-proper

$\mathrm{SNc}$

$\mathrm{SNr}$

sPf

STh

stt

$\mathrm{VA}(\mathrm{pc}, \mathrm{mc})$

VLa
Limitans nucleus

Lateral posterior nucleus

Primary motor cortex

Mammillary body

Mediodorsal nucleus (parvocellular, magnocellular, and paralamellar divisions)

Medial geniculate nucleus

Medial lemniscus

Mammillothalamic tract

Medioventral nucleus

Optic tract

Peri-aqueductal gray

Posterior commissure

Parafascicular nucleus

Prefrontal cortex

Premotor cortex, caudal part

Premotor cortex, rostral part

Posterior nucleus

Pre-supplementary motor area

Pallidothalamic tractotomy

Anterior pulvinar

Medial pulvinar

Putamen

Parvalbumin

Reticular thalamic nucleus

Red nucleus

Superior colliculus

Suprageniculate nucleus

Stria medullaris

Supplementary motor area

Substantia nigra, pars compacta

Substantia nigra, pars reticulata

Subparafascicular nucleus

Subthalamic nucleus

Spinothalamic tract

Ventral anterior nucleus (parvocellular

and magnocellular divisions)

Ventral lateral anterior nucleus
The surgical treatment of motor disorders such as Parkinson's disease (PD) and essential tremor (ES) has evolved over the years, targeting alternatively the motor thalamus, the basal ganglia, and more rarely, subthalamic area. The different approaches are based on extensive knowledge of the motor circuitry and of the pathophysiology known from animal models, such as the MPTP monkey (DeLong 1990; Obeso et al. 2000; Wichmann and DeLong 2003), and peroperative recordings in patients undergoing surgery (Lenz et al. 1994; Jeanmonod et al. 1996; Lozano et al. 1997; Hutchison et al. 1998; Vitek et al. 1998; Magnin et al. 2000, 2001a; Zonenshayn et al. 2000; Garonzik et al. 2002; Kobayashi et al. 2003). The two major motor pathways involved in PD and ET are illustrated schematically in Fig. 1. Their principal access to the thalamus and thalamocortical network is through the pallidothalamic and cerebellothalamic tracts, respectively. The pallidothalamic tract is composed of the ansa lenticularis (al) and of the fasciculus lenticularis ( $\mathrm{fl}$, coursing through field $\mathrm{H} 2$ of Forel), both take their origin in the internal part of the pallidum (GPi). The two fibre tracts merge into the fasciculus thalamicus (ft) (or field $\mathrm{H} 1$ of Forel) before entering the thalamus. The cerebellothalamic tract connects the deep cerebellar nuclei (dentate, interposed, and fastigial nuclei) with the thalamus and courses through the superior cerebellar peduncle, decussates, and passes through and anterior to the red nucleus before reaching the thalamus.

The current knowledge on the pallidothalamic and cerebellothalamic connections is dominantly derived from data in monkeys. Degeneration studies and the use of modern tracing techniques with multiple anterograde and retrograde tracers provided much information about the origin of these fibre tracts and their projections to the thalamus and thalamocortical circuits (Nauta and Mehler 1966; Carpenter et al. 1976; Asanuma et al. 1983a, b; Parent and De Bellefeuille 1983; Ilinsky et al. 1985; Percheron et al. 1993, 1996; Rouiller et al. 1994; Inase and 


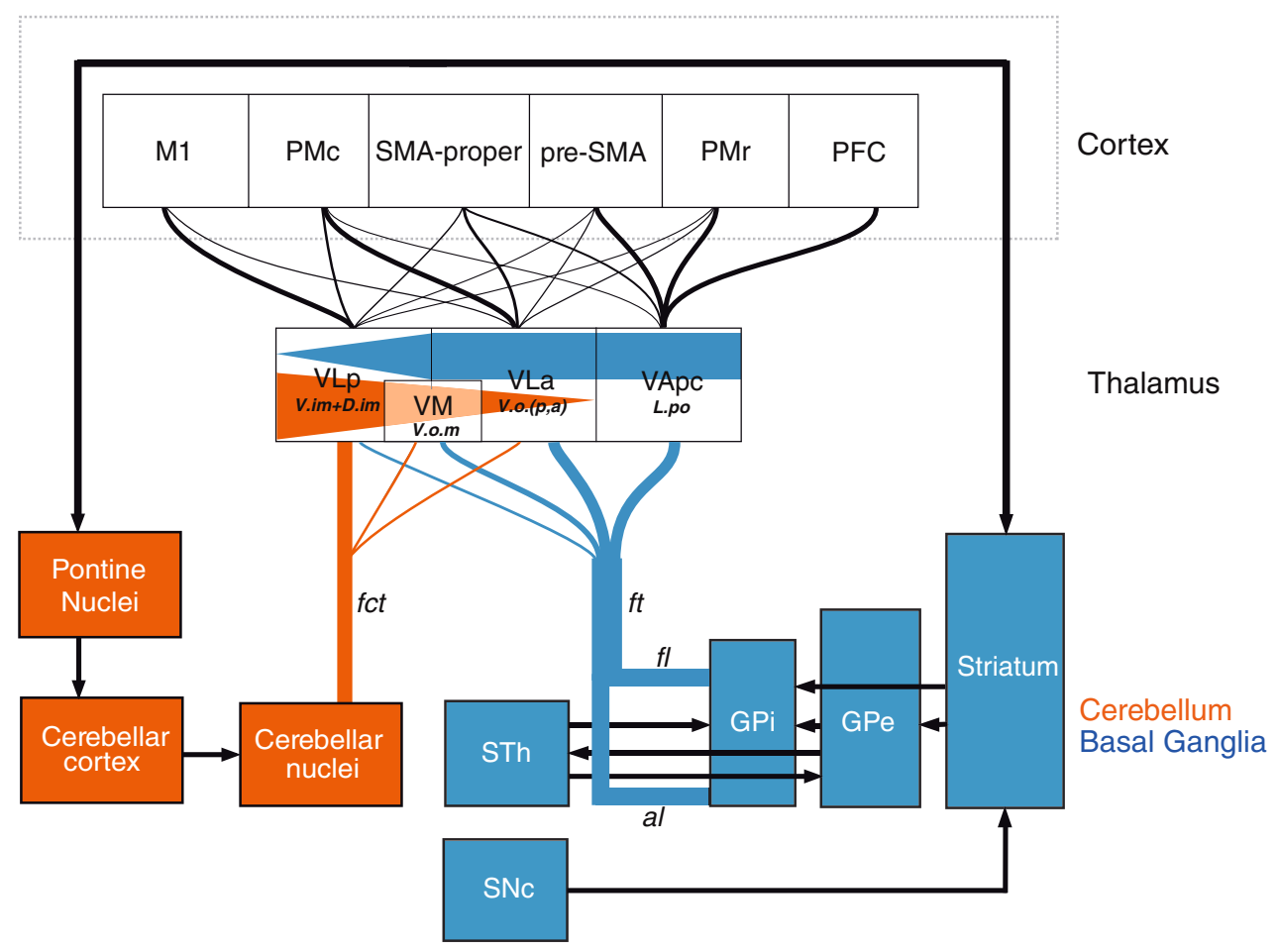

Fig. 1 Simplified diagram of the cortico-cerebello-thalamocortical and cortico-basal ganglia-thalamocortical circuitry based on data derived from tracing studies in monkeys. The cerebellar nuclei project to the motor thalamus via the fasciculus cerebellothalamicus ( $\mathrm{fct}$ ), with primary target in the VLp, but also in VLa and VM (projections to medial thalamic nuclei are not included in the schema). Efferent connections of the GPi to the thalamus course through the ansa lenticularis (al) and the fasciculus lenticularis (fl), and the two fibre bulks merge to form the fasciculus thalamicus (ft) which projects

Tanji 1995; Parent and Hazrati 1995a; Matelli and Luppino 1996; Sakai et al. 1996, 2000; Shink et al. 1997; Sidibe et al. 1997; Middleton and Strick 2000; Baron et al. 2001, 2006; Francois et al. 2002; Haber 2003; Parent and Parent 2004; Calzavara et al. 2005). Thus, more is known about the origin and terminations than the exact pathway of those fibres, particularly in the subthalamic region. In the human brain, the course of the pallidothalamic and cerebellothalamic fibre tracts is still unclear. Indeed the description of the subthalamic fibre pathways in the human brain dates from the late ninteenth and early twentieth centuries (Forel 1877; Von Monakow 1895; Vogt 1909; Vogt and Vogt 1920). The reference to Forel's work ("fields of Forel") is still used to describe the pallidothalamic fibre system.

Targeting the pallidothalamic and cerebellothalamic tracts for surgical treatment of PD and ET was already explored with some success in the 1950s-1970s (Spiegel and Wycis 1954; Spiegel et al. 1963; Mundinger 1965; Velasco et al. 1972; Bertrand et al. 1973) but with a limited precision due to poor technical support at the time. This surgical approach was reappraised in the last 10 years based on pathophysiological evidence of dysfunctional primarily to the VLa, VApc, and VM nuclei, with only minor projections to the VLp (projections to the intralaminar nuclei are not shown). Equivalent Hassler's nomenclature (Hassler 1982) for thalamic nuclei is also indicated. Connections to the thalamus and cortex are represented with different thicknesses according to their relative density and by different gradients in the thalamus. The two major motor pathways are also represented by different colors for clarity. See list of abbreviations

thalamocortical system (thalamocortical dysrhythmia, TCD) following thalamic cells deactivation, in case of ET, or cell overinhibition, in case of PD (Magnin et al. 2001a, 2001b; Aufenberg et al. 2005). This pre-thalamic approach maximizes the disinhibition of the thalamus with a lesion of the pallidothalamic fibers, that is, at least three times smaller than the size of a pallidal lesion that would include the sensorimotor and the associative territories (Francois et al. 1994; Parent and Hazrati 1995a; Gross et al. 1999; Karachi et al. 2002; Morel et al. 2002). The relevance of the motor fiber tracts in the subthalamic area in surgical approach for motor disorders is also supported by recent reports on DBS [or in rare cases, of radiofrequency lesions (RFL)] of the subthalamic nucleus (STh) in PD, where the best clinical effect is obtained when the lesion or DBS electrode contact is dorsal to STh and involves at least part of the pallidothalamic fibres (H2 or fl) (Voges et al. 2002; Hamel et al. 2003; Zonenshayn et al. 2004; Alvarez et al. 2005; Breit et al. 2006; Godinho et al. 2006; Herzog et al. 2007a). Furthermore, direct targeting of the posterior subthalamic area has also recently been reported to be clearly more efficient than thalamic DBS in ET (Hamel et al. 2007; Herzog et al. 2007b). 
In order to gain more knowledge about the course of the pallido- and cerebellothalamic tracts and their stereotactical positions in the subthalamic region, we conducted an anatomical study in human post-mortem brain using myelin staining techniques, immunohistochemical procedures and the Morel's atlas of the human thalamus and basal ganglia (Morel et al. 1997; Morel 2007). The histological demonstration of the fibre tracts was also correlated with high-resolution post-mortem MRI and the variability of their trajectory and position in different brains was evaluated.

\section{Materials and methods}

This study is based on post-mortem examination of five brains from normal subjects with no history of neurological diseases or pathological signs at autopsy. The characteristics of the subjects (age, cause of death, post-mortem delays) are given in Table 1, except for case $\mathrm{Hb5}$, for which these informations were lacking. This case, however, showed no pathological signs by post-mortem examination and was included for correlations with highresolution MRI obtained prior to histological processing.

The procedures for fixation, stereotactic blocking, and sectioning follow those described previously (Morel et al. 1997, 2002; Morel 2007). In brief, whole brains were fixed for 2-3 weeks in paraformaldehyde (PAF) $4 \%$ in $0.1 \mathrm{M}$ phosphate buffer (PB) or in formalin $10 \%$ for few weeks to several months. After interhemispheric section, a special guillotine was used to make blocks of the thalamus and basal ganglia in planes parallel or orthogonal to the reference stereotactic plane (i.e. passing through the centers of the anterior and posterior commissures). The blocks were then postfixed 2-3 days (for PAF fixed brains) and cryoprotected over 2-3 weeks in increasing (10, 20, and $30 \%$ ) sucrose concentrations in PB or in formalin. Except for two blocks that were frozen in cryostat, all other were frozen by immersion in isopentane at $\sim-30^{\circ} \mathrm{C}$ and then stored at $-75^{\circ} \mathrm{C}$. Sections were cut at 40 or $50 \mu \mathrm{m}$ and from six to nine series (300-500 $\mu \mathrm{m}$ intervals between series) were collected in PB. Adjacent series were stained for Nissl with cresyl violet and for myelin with a modified $\mathrm{He}$ idenhain procedure applied to free-floating or mounted sections (Hutchins and Weber 1983; Burgel et al. 1997). The two myelin staining methods were applied in case $\mathrm{Hb} 5$, the first for its lower background and finer fibre staining (see Fig. 2), the second to reduce section shrinkage and deformation due to successive alcohol treatments. The shrinkage factor due to free-floating myelin processing, which was evaluated by measuring distances on adjacent free-floating and mounted myelin sections (in case Hb5) amounted to $7 \%$. Mounted myelin sections were similar to Nissl stained sections. The overall deformation due to histological processing was evaluated by comparing distances measured in MRI and in corresponding Nissl stained sections. This was minimal (1.02) within the plane of section but slightly higher for distances measured across sections (as also reported in Morel 2007). Other series were processed for acetylcholinesterase (AChE) with a modified Koelle-Friedenwald method (Mesulam 1982), or immunocytochemically with antibodies against calcium-binding proteins $(\mathrm{CaBP})$ and the non-phosphorylated neurofilament protein (with SMI-32) (see Table 1).

Table 1 List of brains and histological procedures

\begin{tabular}{|c|c|c|c|c|c|c|c|}
\hline Case No. & $\begin{array}{l}\text { Age (years)/ } \\
\text { gender }\end{array}$ & PM delay (h) & $\begin{array}{l}\text { Cause of } \\
\text { death }\end{array}$ & $\begin{array}{l}\text { ac-pc } \\
(\mathrm{mm})^{\mathrm{a}}\end{array}$ & Fixation & $\begin{array}{l}\text { Hemisphere/plane } \\
\text { of section }\end{array}$ & Histology $\mathrm{y}^{\mathrm{b}}$ \\
\hline $\mathrm{Hb} 1$ & 70/female & $<24$ & Coronary infarct & 25 & Formalin & $\begin{array}{l}\mathrm{L}^{\mathrm{e}} / \mathrm{SAG} \\
\mathrm{R}^{\mathrm{e}} / \mathrm{HOR}\end{array}$ & $\mathrm{CaBP}$ \\
\hline $\mathrm{Hb} 2$ & 57/female & $<24$ & Lung carcinoma & 30 & Formalin & $\begin{array}{l}\text { R/FRO } \\
\text { L/HOR }\end{array}$ & $\mathrm{CaBP}$ \\
\hline $\mathrm{Hb} 3$ & 74/female & 4 & Lung carcinoma & 24 & PAF & $\begin{array}{l}\text { R/HOR } \\
\text { L/SAG }\end{array}$ & CaBP/SMI/AChE \\
\hline $\mathrm{Hb} 4^{\mathrm{c}}$ & 59/female & 16 & Anal carcinoma & 26 & PAF & $\begin{array}{l}\mathrm{R}^{\mathrm{e}} / \mathrm{SAG} \\
\mathrm{L}^{\mathrm{e}} / \mathrm{FRO}\end{array}$ & $\mathrm{CaBP} / \mathrm{SMI} / \mathrm{AChE}$ \\
\hline $\mathrm{Hb} 5^{\mathrm{d}}$ & - & - & - & 24 & Formalin & $\begin{array}{l}\mathrm{R}^{\mathrm{e}} / \mathrm{HOR} \\
\mathrm{L}^{\mathrm{e}} / \mathrm{FRO}\end{array}$ & $\mathrm{CaBP} / \mathrm{SMI}$ \\
\hline
\end{tabular}

\footnotetext{
"Intercommissural (ac-pc) distances are indicated in millimeters "in vivo"

${ }^{\mathrm{b}}$ Staining procedures additional to standard Nissl and myelin

c Post-mortem 3 T 3D T1-weighted MRI (see protocol in "Materials and methods")

d Post-mortem 3 T proton-density MRI (see protocol in "Materials and methods")

e Hemispheres used for stereotactic mapping
} 
Fig. 2 Series of frontal sections stained for myelin and arranged from anterior (upper left) to posterior (lower right), with corresponding coordinates given in millimeters anterior to the posterior commissural level (Table 1; case $\mathrm{Hb} 4)$. The pallidothalamic fibres are seen from their emergence from the GPi (al and fl, levels A 21.0-

A 13) to their entry into the thalamus (ft, levels A 15-A 12). The cerebellothalamic (fct) tract is shown at its most posterior entrance into the thalamus (near the VPM, level A 6.0) and more anteriorly, into VLp (level A 7.5). Other fibre tracts (mtt, fx, ap, ot, and ac) are also clearly recognizable. Scale bar (in upper left panel): $3 \mathrm{~mm}$
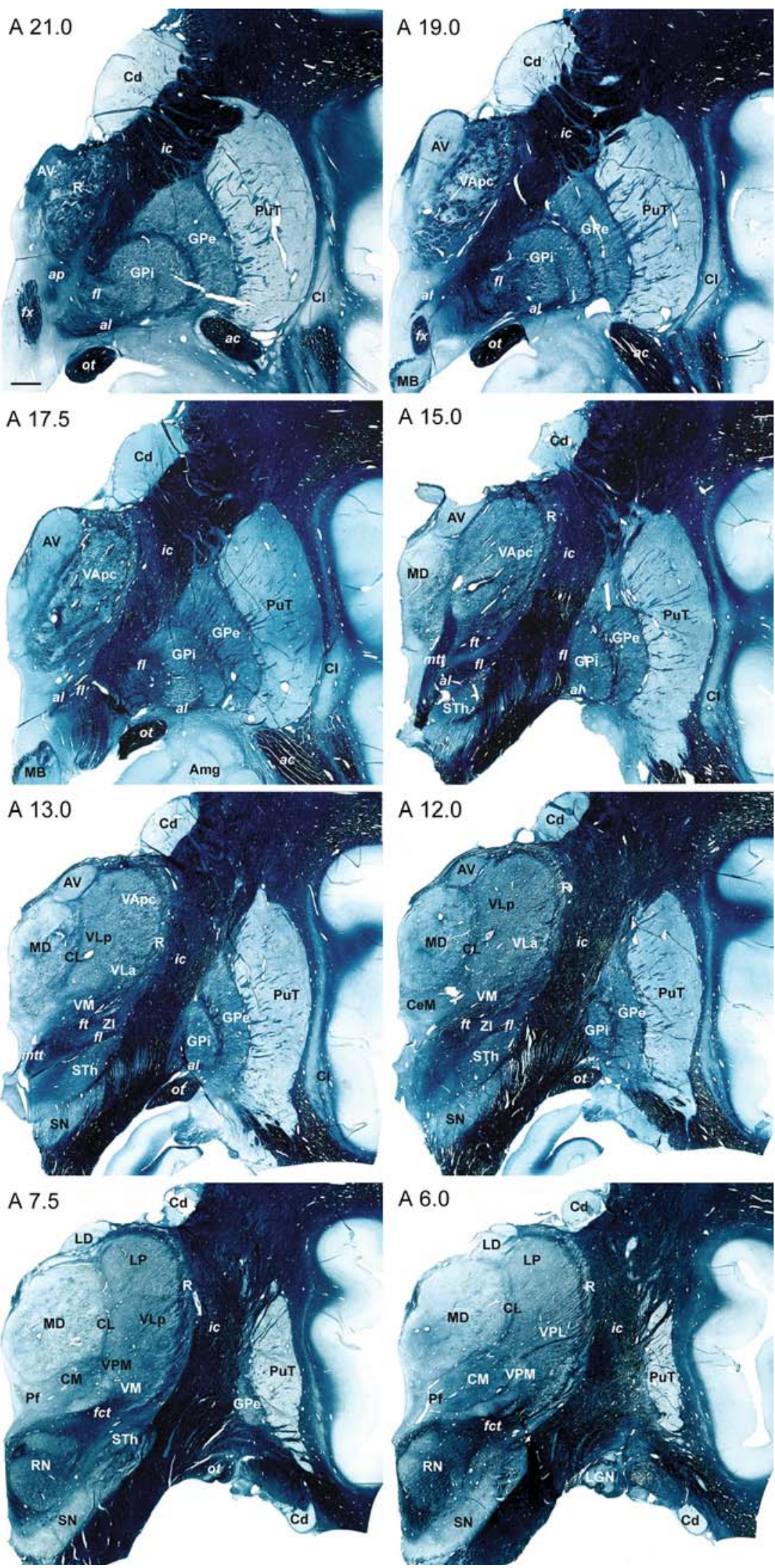
Immunocytochemistry

The procedures follow those described previously (Morel et al. 1997, 2002; Morel 2007). Prior to be exposed to antibodies, some series were pre-treated for $10 \mathrm{~min}$ by exposure to microwave in a $4 \%$ aluminium chloride solution (Evers and Uylings 1994) to improve antigen retrieval in formalin stored sections. All series for immunocytochemistry were preincubated $10 \mathrm{~min}$ in $1.5 \% \mathrm{H}_{2} \mathrm{O}_{2}$ to remove endogenous peroxidase activity. After several rinses in phosphate buffered saline ( $\mathrm{pH} 7.4)$, sections were incubated $48 \mathrm{~h}$ at $4^{\circ} \mathrm{C}$ or $24 \mathrm{~h}$ at room temperature in primary antibodies (dilutions 1:1,000-1:5,000; depending on the antibody and tissue fixation), $2 \%$ normal horse or goat serum; and $0.2 \%$ triton-X-100. The antibodies used were mouse monoclonal antibodies directed against parvalbumin (PV) or calbindin (CB) (SWant, Bellinzona, Switzerland or Sigma, St Louis, MO, USA), rabbit polyclonal against calretinin (CR) (SWant), mouse monoclonal against the nonphosphorylated neurofilament protein (SMI32; Sternberger Monoclonals Inc., Covance Research Products Inc., Princeton, USA). After several rinses, sections were incubated $30-60 \mathrm{~min}$ at room temperature in biotinylated secondary antibodies (1:200, Vector Laboratories, Burlingame, CA, USA) and stained with the avidin-biotin complex (ABC) immunoperoxidase method (Vectastain Elite kits, Vector Laboratories). The reaction was visualized with 3,3'-diaminobenzidine tetrahydrochloride as chromogen, diluted $0.05 \%$ in $0.05 \mathrm{M}$ Tris-saline $(\mathrm{pH} 7.7)$ and $0.001 \% \mathrm{H}_{2} \mathrm{O}_{2}$. As controls, the primary antibody was omitted while the rest of the procedure remained the same.

Data analysis

Contours of Nissl stained sections were drawn with a Wild stereomicroscope (Leica) equipped with a camera lucida, or traced on scanned images of the sections using Adobe Photoshop (version CS2) and Adobe Illustrator (version CS2). Then, adjacent sections were superimposed using contours and blood vessels. The different fibre tracts (pallidothalamic, cerebellothalamic, and medial lemniscus/ spinothalamic) were delineated on myelin stained sections and the contours superimposed on multiarchitectonic and stereotactic maps of the thalamus and basal ganglia (see Morel 2007 for graphical representations, parcellations and nomenclature). We adopted a Latin nomenclature for the cerebello- and pallidothalamic tracts, i.e. fasciculus cerebellothalamicus (fct) for the first; and fasciculus lenticularis (fl), fasciculus thalamicus (ft), and ansa lenticularis (al) for the second. The delimitation was based on similar criteria for all cases, i.e. corresponding to the thick part of the tract (or "bulk of the tract", as shown in Fig. 3a, c), whether at pallidal or subthalamic level. The entrance into the thalamus was traced for only part of the tract in clear continuity with the prethalamic fibres. Adjacent sections processed for $\mathrm{AChE}, \mathrm{CaBP}$ or SMI-32 provided additional criteria for fibre tract delimitation, as well as for the subcompartmentalisation of the basal ganglia and
Fig. 3 Representation of the cerebellothalamic (fct) and pallidothalamic (al, fl, ft) tracts on sagittal section of the atlas (panel c) as delimited from myelin (area comprised in the rectangle in a). Thalamic nuclei and STh were best identified on adjacent Nissl section (panel $\mathbf{b}$ ). Panel d shows PV

immunostaining at same sagittal level. The arrows in a and $\mathbf{d}$ point to a small gap separating the fct and $\mathrm{ft}$, visible in myelin and PV-ir, respectively. Notice some PV-ir enhanced fibres in the internal capsule near the anterior pole of the STh and presumably corresponding to the fasciculus subthalamicus. Scale bars (a and c): $2 \mathrm{~mm}$
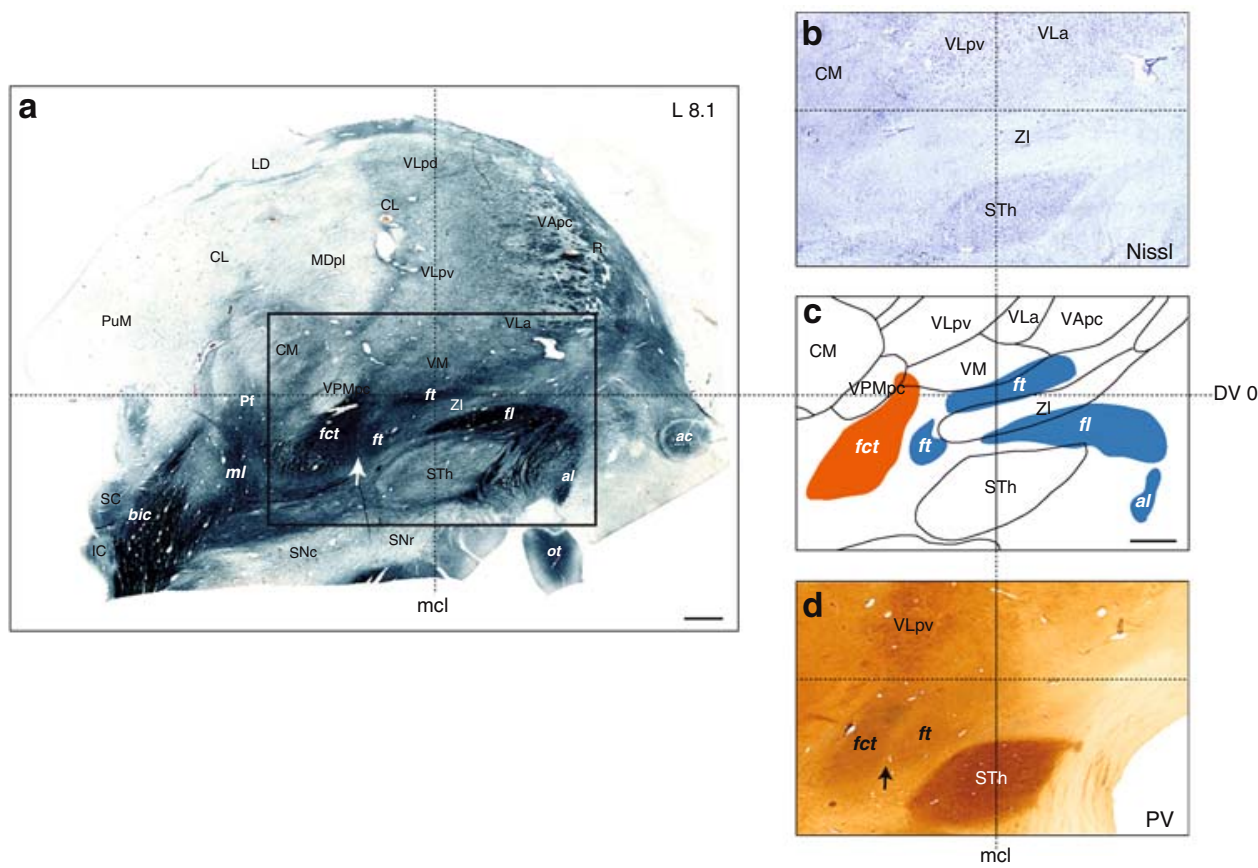
refined thalamic nuclear parcellation (e.g. Fig. 4). For illustrations, scanned images were adjusted for contrast and brightness with Adobe Photoshop and transferred as computer files to the software Adobe Illustrator for production of the final montage.

\section{Magnetic resonance images}

In two autopsy brains (Table 1, Hb4 and Hb5), MR images were acquired with a 3-Tesla scanner (Philips). Whole brains were placed in a plastic bag filled with $4 \%$ PAF or neutral formalin and maintained in the scanner with foam pieces. For the first case (Hb4), T1-weighted MRI in the three stereotactic planes were acquired with the following parameters: FOV $220 \mathrm{~mm}$; $400 \times 400$; TSE factor 15; TR 3,000 ms; TE 80; thickness $2 \mathrm{~mm} / 0$ gap; acquisition voxel: $0.55 / 0.56 / 2.0 \mathrm{~mm}$; and total scan time: $3 \mathrm{~h}$. For the second case (Hb5), a protocol for high-resolution proton density (PD) MRI was used: 2D multislice acquisition; FOV: $160 \mathrm{~mm}$; matrix: $528 \times 528$; 52 coronal and 32 axial slices; thickness $1.25 \mathrm{~mm} / 0$ gap; TR 3,000 ms; TE 24; acquisition voxel size: $0.30 \times 0.30 \mathrm{~mm}$ (coronal) and $0.31 \times 0.31$ (axial); and scan time $5 \mathrm{~h}$ for each series (coronal and horizontal).

\section{Results}

Cerebellothalamic tract

The cerebellothalamic tract, or brachium conjuntivum, originates in the dentate, interposed and fastigial cerebellar nuclei. The cerebellothalamic tract ascends through the superior cerebellar peduncle, crosses (most of the fibres) over its decussation, passes through and anteriorly to the red nucleus and then rises into the thalamus. To ease the description, we adopted a Latin nomenclature for the subthalamic fibre systems, i.e. the cerebellothalamic fibre bulk is called "fasciculus cerebellothalamicus" (fct) from the level of the red nucleus (RN) to its entrance into the thalamus.

The fct was traced on the basis of myelin stained sections, from the dorsal border of the $\mathrm{RN}$ to the thalamus.
Fig. 4 a Sagittal atlas map and b photomicrographs of adjacent sections stained for myelin, d $\mathrm{AChE}$ and $\mathbf{c}$ immunoreacted for SMI-32, e CR, and f CB. Case Hb3. Scale bar (upper left panel): $2 \mathrm{~mm}$
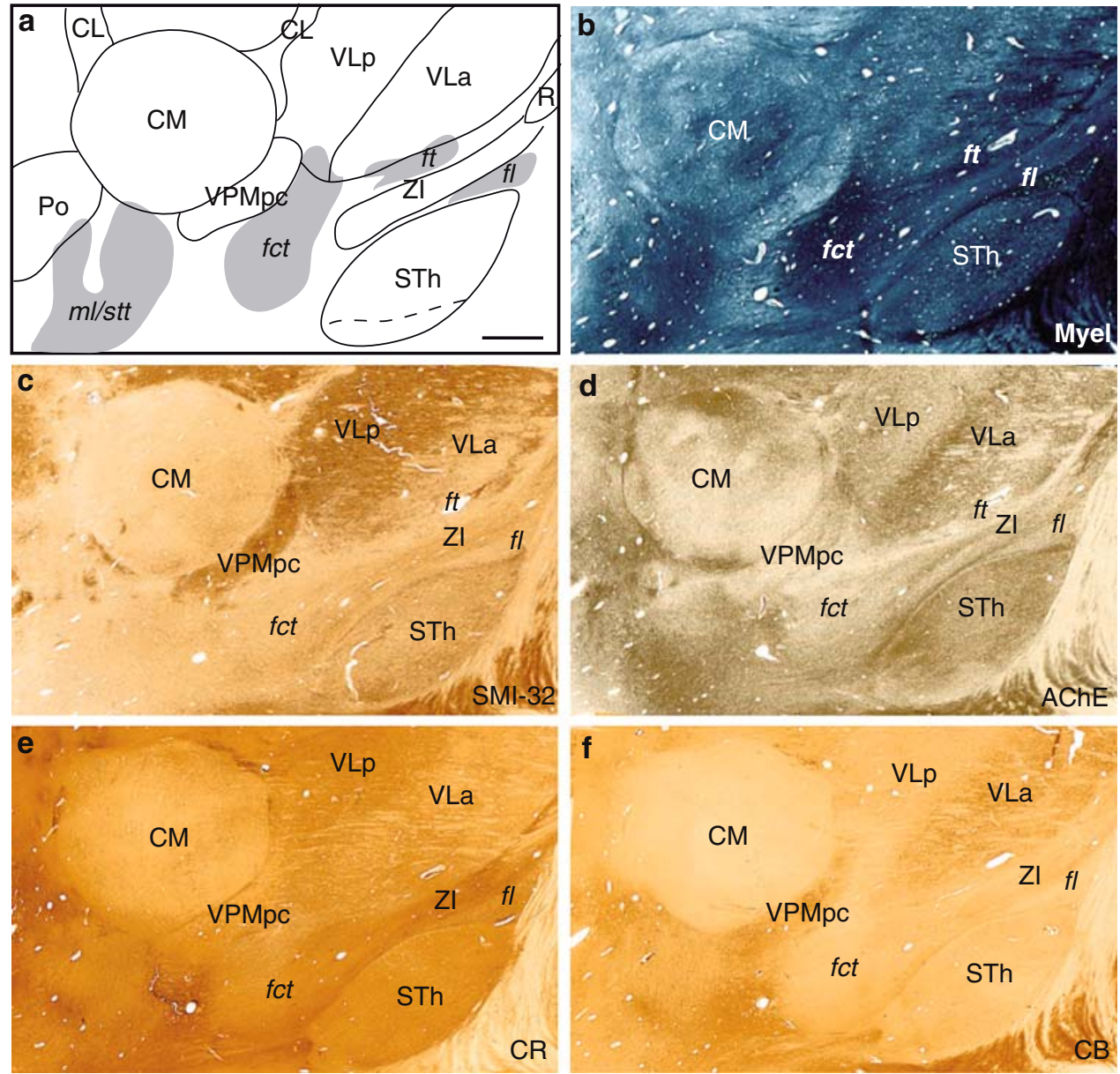
Overall, the trajectory of the tract can be relatively easily followed; it climbs into the thalamus with a posteromedial to anterolateral direction. On sagittal sections, the main orientation of the tract is posteroventral to anterodorsal, with a $60^{\circ}-65^{\circ}$ angle with the intercommissural plane (Fig. 5). The relative stable anteroposterior position of the fct at mid-distance between the posterior commissure (pc) and midcommissural level $(\mathrm{mcl})$ is recognizable in horizontal sections (Fig. 6). On frontal sections, the orientation is medioventral to laterodorsal, with a $40^{\circ}-45^{\circ}$ angle with the intercommissural plane (Figs. 2, 7). In myelin stain, the entrance of the fibres is clearly seen in the ventral division of the ventral lateral posterior (VLpv) nucleus (Fig. 5, sagittal planes L10.8 and L11.7) with a possible extension into the ventral lateral anterior (VLa) nucleus (e.g. Figs. 4a; 5, L9 and L9.9). On its way to the VLp, most of the fct passes ventral to the subparafascicular ( $\mathrm{sPf}$ ) nucleus, anterolaterally to the parvocellular part of the ventral posterior medial (VPMpc) and VPM nuclei, and through the ventral medial nucleus (VM) at level posterior to the subthalamic nucleus and the zona incerta (ZI) (Fig. 5). It is interesting to note that at the dorsal border of the $\mathrm{RN}$, a part of the fct seems to take a medial turn towards the centre médian nucleus (CM) (Fig. 2, section A6.0).

In adjacent sections stained for $\mathrm{AChE}$ or immunoreacted for $\mathrm{CaBP}$, the fct appears generally negative, except for
PV-immunoreactivity (PV-ir), which also characterizes the $\mathrm{RN}$ and $\mathrm{STh}$, as described below.

\section{Pallidothalamic tract}

The pallidothalamic tract was traced from its origin in the GPi and divided into two bundles according to previous descriptions (Vogt 1909; Vogt and Vogt 1920; Nauta and Mehler 1966): the ansa lenticularis (al) and the fasciculus lenticularis (fl). The al, which represents the ventral division of the ansa lenticularis of von Monakow leaves the internal pallidum at its anteroventral edge and courses anteromedially around the posterior limb of the internal capsule (Figs. 8, 9). Its origin in the pallidum appears to extend from far rostral to near the caudal end of GPi, and from both medial and lateral subdivisions of the nucleus. From the internal capsule, the al continues posterodorsally to take a sharp descending, then an ascending turn toward the thalamus where it is joined by the fibres of the $\mathrm{fl}$ arriving over the dorsal edge of the subthalamic nucleus. The fl (or field $\mathrm{H} 2$ of Forel) leaves the GPi dorsal to al (Fig. 2, A21.0 and A19.0; Fig. 8, A17.5) and represents the dorsal division of the ansa lenticularis of von Monakow. Its emergence from GPi seems to extend not as far rostrally as that of al. Although the precise course of the fl through the

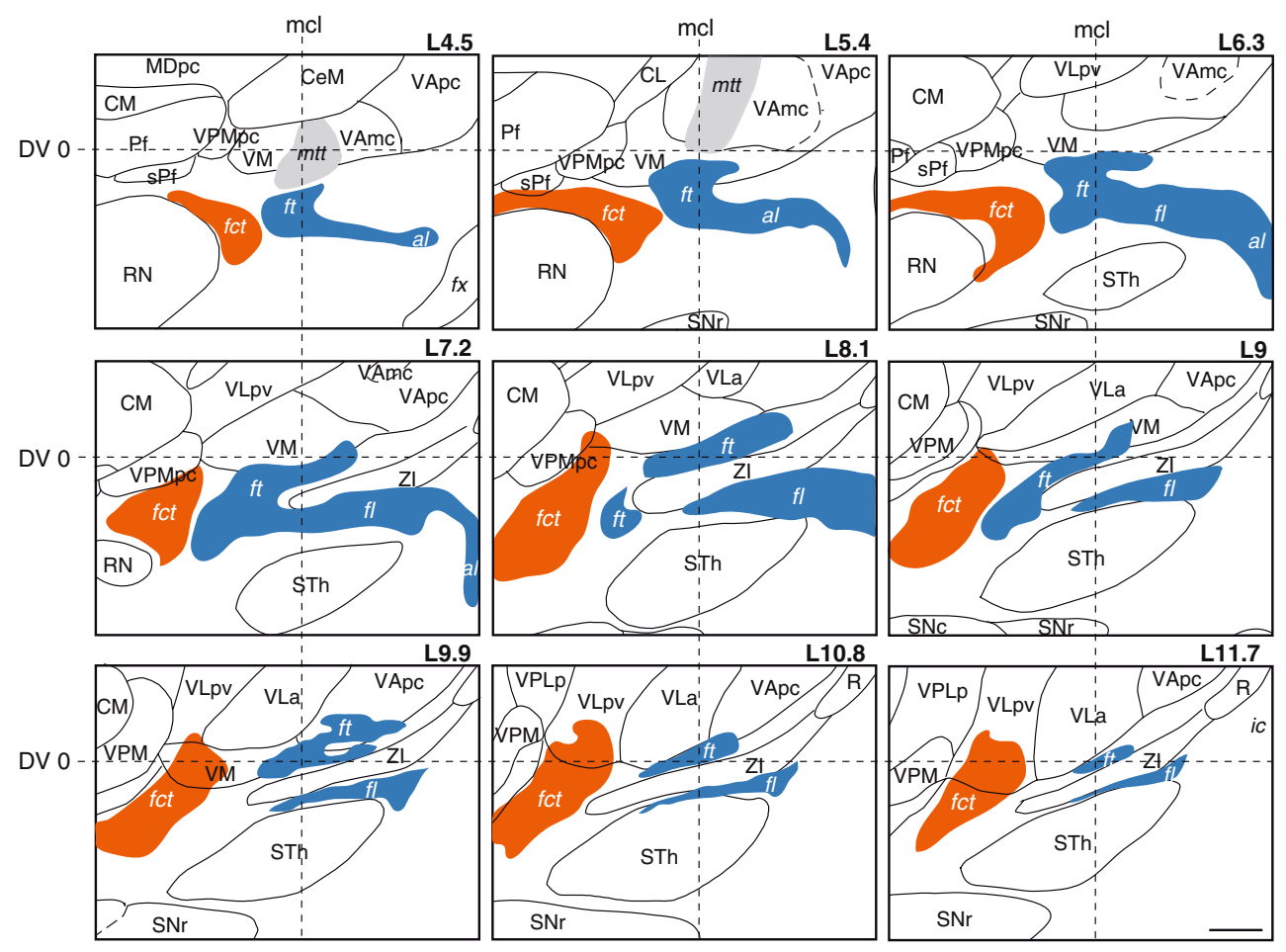

Fig. 5 Pallidothalamic (blue) and cerebellothalamic (orange) tracts drawn on the atlas of the human thalamus (case $\mathrm{Hb} 1$ ). The sagittal maps are arranged from medial (L4.5) to lateral $(\mathrm{L} 11.7 \mathrm{~mm})$ with
$0.9 \mathrm{~mm}$ intervals. The maps are centered on the midcommissural (mcl) and intercommissural (DV0) lines. Scale bar (lower right panel): $2 \mathrm{~mm}$ 

and cerebellothalamic (orange) tracts drawn on horizontal sections of the atlas at intercommissural level (DV0) and four levels ventral to DV0 (V0.9, V1.8, V2.7, and V3.6). The horizontal planes are projected on a sagittal section of the atlas $8.1 \mathrm{~mm}$ distant from the ventricular border (L8.1) in lower right panel. The $\mathrm{pc}$ and mcl levels are represented on the horizontal and sagittal maps by dotted lines. Scale bars (lower right panels): $2 \mathrm{~mm}$
Fig. 6 Pallidothalamic (blue)
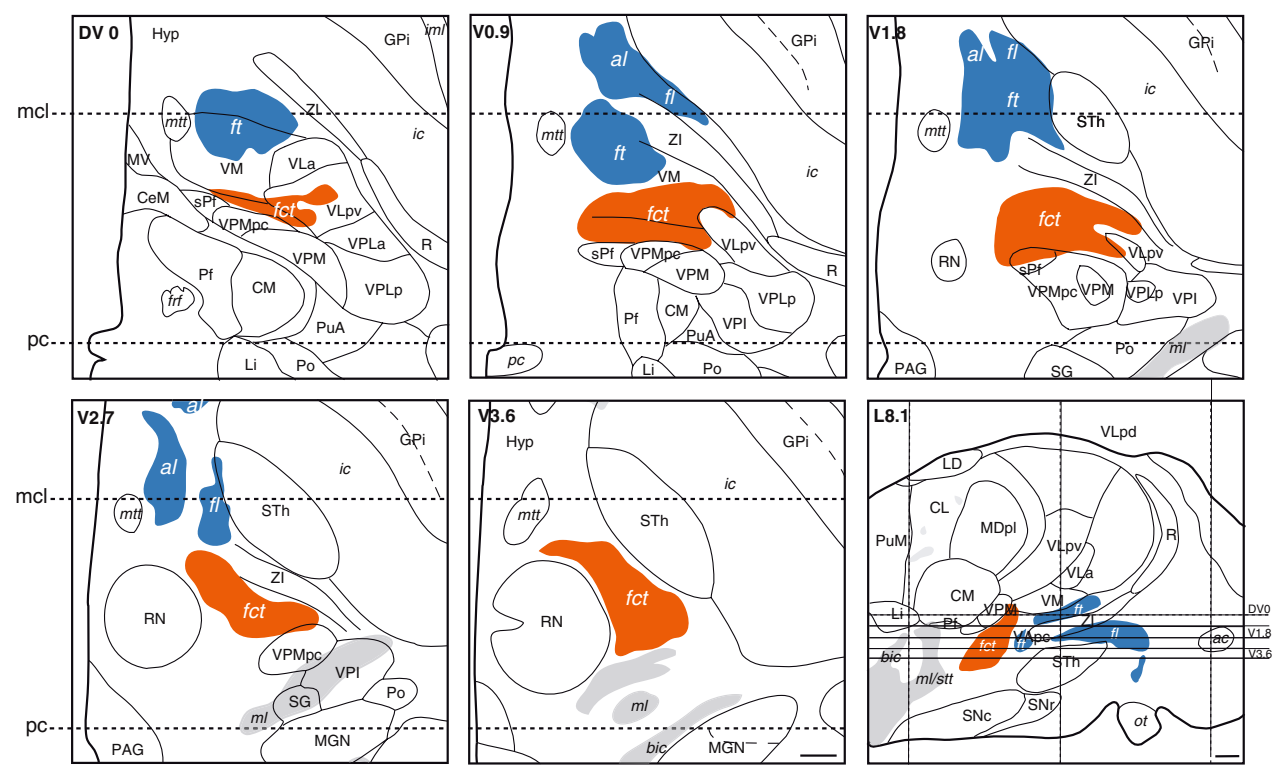

Fig. 7 Series of frontal highresolution proton density postmortem MRI (left column), myelin sections (middle column), and atlas maps (right column) of the same brain (Table 1; Hb5), at corresponding anteroposterior levels from posterior (lower panels) to middle part of the thalamus (upper panels). Coordinates indicated in the left column (A2.5, A5, and A7.5) correspond to millimeters anterior to the posterior commissural level. The cerebellothalamic tract (fct) can be identified, as well as the RN and several thalamic nuclei. Scale bars (left column): $10 \mathrm{~mm}$
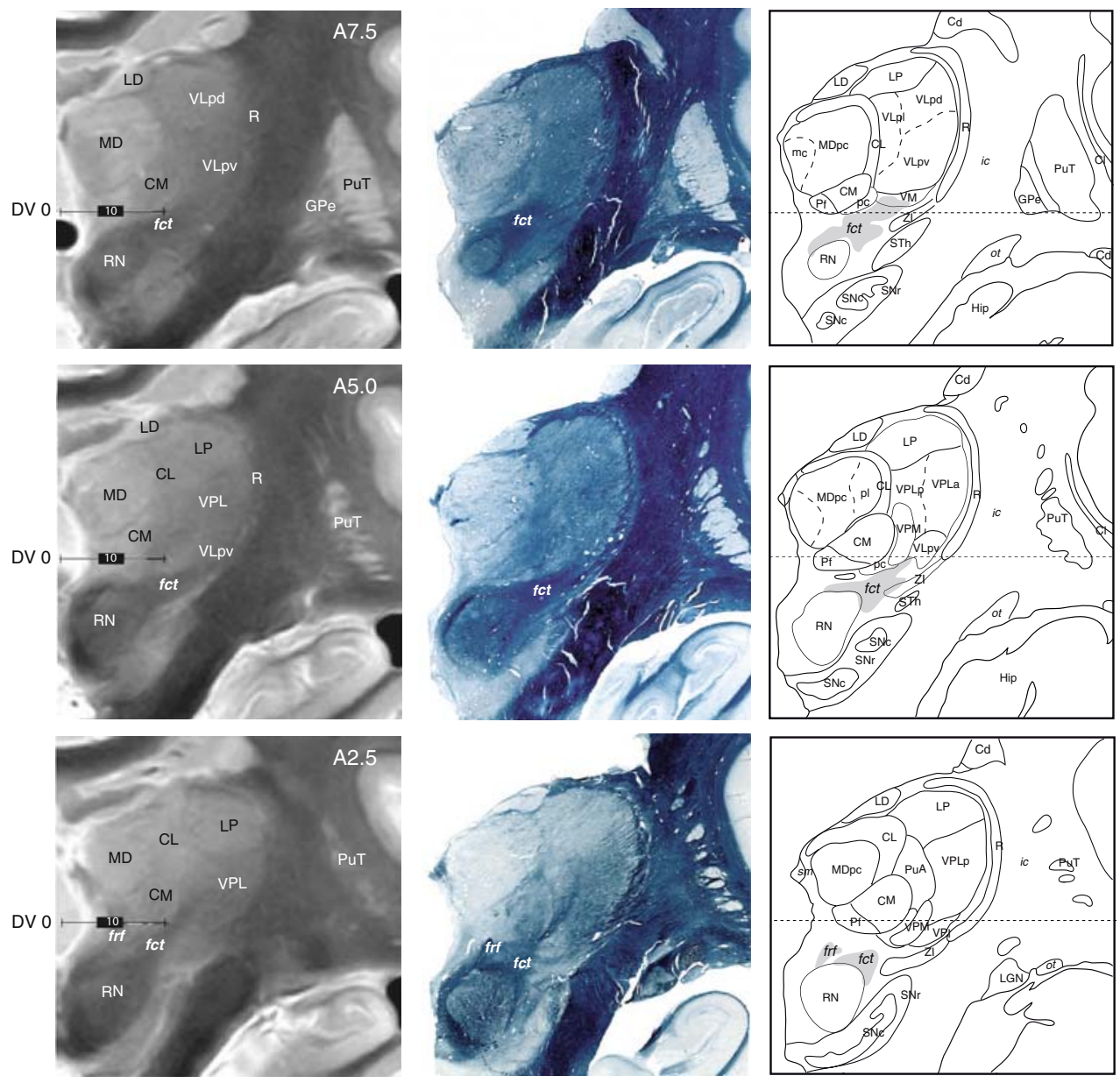

internal capsule cannot be determined on myelin sections as it is embedded within the capsular fibres, it seems to cross the internal capsule nearly horizontally and then runs dorsal to the subthalamic nucleus and ventral to ZI in a posteroventral direction, joining the al to form the fasciculus thalamicus ( $\mathrm{ft}$ ). The term $\mathrm{ft}$ thus characterizes all pallidothalamic fibres entering the ventral thalamus, regardless of their ansal or fascicular origin. The $\mathrm{ft}$ reaches 
Fig. 8 Anterior continuation of the series shown in Fig. 7 to illustrate MRI correlations of pallidothalamic fibre tracts (al, $\mathrm{fl}$, and $\mathrm{ft}$ ), thalamic nuclei, and basal ganglia. Same conventions as in Fig. 7. Scale bars (left column): $10 \mathrm{~mm}$
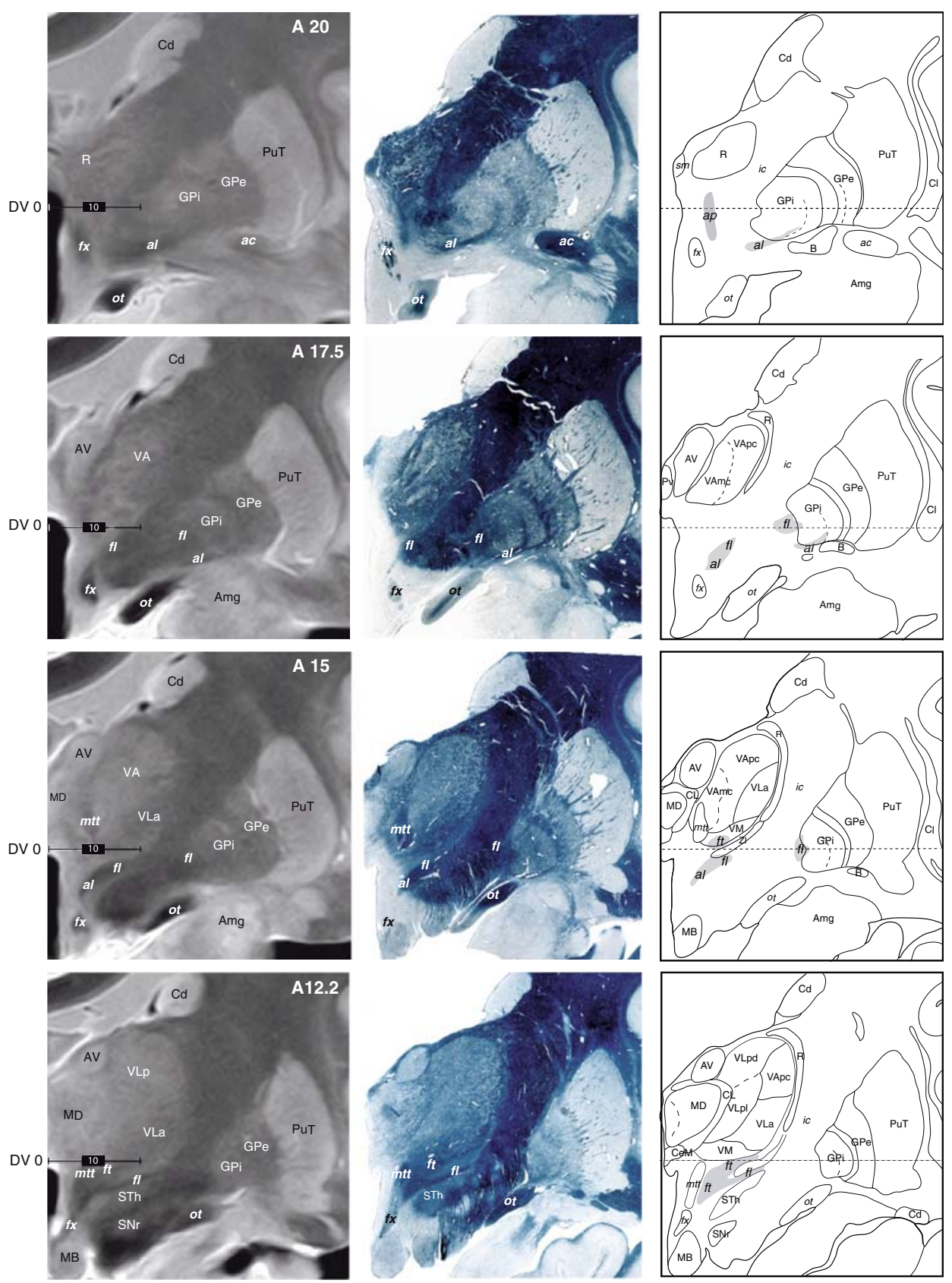

mainly the parvocellular division of the ventral anterior (VApc) and VLa nuclei through the anterior part of the VM nucleus (Fig. 5, L9 and L9.9).

In relation to the classic nomenclature, Forel field $\mathrm{H} 2$ corresponds to the emergence of fl fibres from the internal capsule. The field H1, on the other hand, is more difficult to relate with the al or $\mathrm{fl}$ because it contains both fibre bundles. The most medial component of the $\mathrm{ft}$ seems to arise from al more than fl (Fig. 5, L4.5, L5.4, and L6.3), which in turn joins the ft more laterally (Fig. 5, L7.2 and L8.1). Whether this apparent mediolateral gradient persists at the entrance of the tract into the thalamus cannot be determined at this point. At most posterior and medial levels (e.g. Fig. 5,
L7.2), the pallidothalamic fibres form the so-called "H1 + H2" field of Forel. At this level, the ft is not yet joined by all of the fl fibres. The transition between this part of $\mathrm{ft}$ and the ansa, as well as with $\mathrm{ft}$ proper containing both $\mathrm{fl}$ and al fibres, is unclear and cannot be identified on the basis of the present data. As best seen in the horizontal plane, the $\mathrm{ft}$ tract comes close to the mammillothalamic (mtt) tract which courses toward the anteroventral (AV) nucleus. This close vicinity of the two tracts occurs near midcommissural level ( $\mathrm{mcl}$; Fig. 5, sagittal planes L4.5 and L5.4; Fig. 6).

The al, fl, and ft are generally unstained with different markers, except for slight PV-ir in $\mathrm{ft}$ at subthalamic level (Fig. 3d). At pallidal level, the "negative" staining of al is 


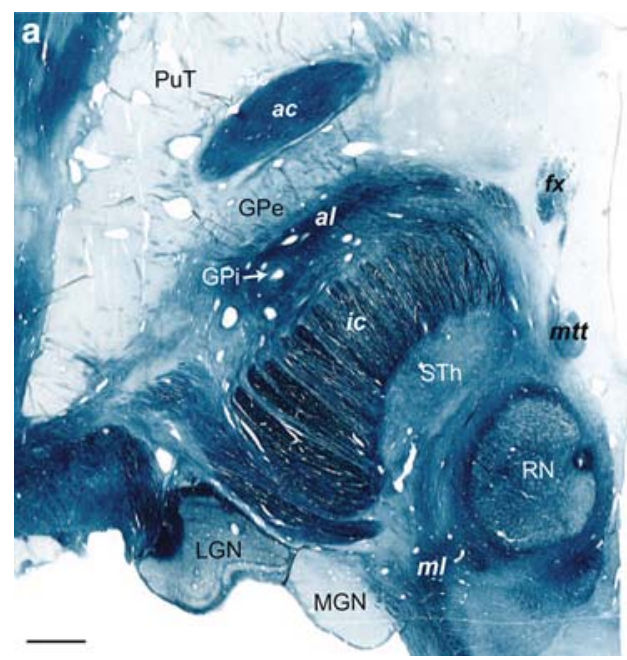

Fig. 9 a Illustration of the pallidal emergence of al in horizontal and b frontal sections stained for myelin. The levels are $4.5 \mathrm{~mm}$ ventral to the intercommissural plane (in a) and $22 \mathrm{~mm}$ anterior to pc (in b).

clearly in contrast with the very intense CR-ir in the sublenticular area, associated with the extended amygdala defined by others (Heimer et al. 1997; Alheid 2003), as well as with enhanced CB-ir in the GPi (see Fig. 10c, d). The CR-ir fibre tract ascending into the thalamus at the same level and which is continuous with the sublenticular CR-ir fibres (Fig. 10d) corresponds to the ansa peduncularis (ap) known to connect the amygdala to the mediodorsal (MD) and reticular (R) thalamic nuclei.

\section{Striatonigral and pallidosubthalamic fibres}

Two other fibre systems related to the basal ganglia are the pallidosubthalamic and striatonigral fibres, which are part of the so-called "comb system" (Nauta and Mehler 1966). Pallidosubthalamic fibres form the fasciculus subthalamicus, which was associated with the middle division of the ansa lenticularis of von Monakow (1895) and connects the external pallidum (GPe) to the STh. The tract cannot be distinguished from the fl at its emergence from the GPi, but further posteriorly and medially, can be seen as thick myelin bundles coming into the STh, ventral to the fl and dorsal to al (Figs. 3a, 11a). In contrast to $\mathrm{fl}$ and al, which remain largely unstained, some of pallidosubthalamic fibres are characterized by enhanced PV-ir and can be traced through the internal capsule up to the level of the subthalamic nucleus, which itself contains very high level of PV (Figs. 3d, 11d). Interestingly, these PV-ir fibres appear in negative contrast to the thick myelinated fibres seen at the same level (Figs. 3a, 11a). The tract corresponding to this position contained very dense degenerated fibres after lesion of GPe (Morel et al. 2001).

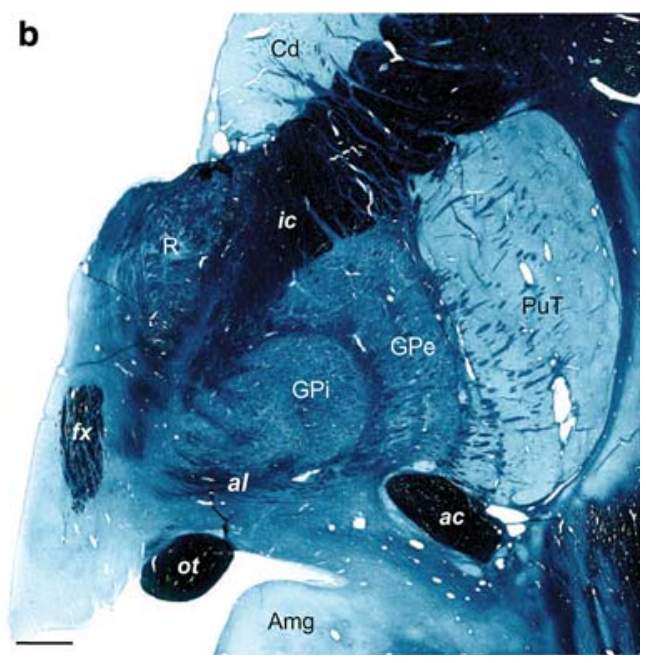

Note the relatively large anteroposterior extent of the al at the ventral limit of the GPi in a. Cases Hb5 (left panel) and Hb4 (right panel). Scale bars: $3 \mathrm{~mm}$

The large fibre bundles characterized by high CB-ir and AChE staining reaching the substantia nigra (SN) correspond to the striatonigral fibres described previously (Morel et al. 2002). In the subthalamic area, these fibres run ventral to the STh and to the fasciculus subthalamicus to continue posteriorly toward the $\mathrm{SN}$, as shown in Fig. 11b. Through not illustrated in the present report, these fibres can be followed from their origin in the striatum (mostly from the posterior two-third of the putamen), through the two pallidal segments and the internal capsule, to their entry in the pars reticulata $(\mathrm{SNr})$. The striatonigral fibres are also enhanced in SMI-32-ir, while only moderately for PV- and CR-ir (Figs. 4c, e; 11d). They appear largely unstained in myelin (Fig. 11a), which is presumably related to their smaller size.

\section{MRI correlations}

High-resolution proton density MRI was obtained from one brain (Hb5, Table 1; see also MRI acquisition protocole in "Materials and methods") prior to guillotine sectioning and histological processing. After MRI acquisition, one hemisphere was cut in the frontal plane and the other in the horizontal plane. The MRI slices (1.3-mm thick) were correlated with the closest myelin stained sections and drawings of the same brain. Examples of these correlations are shown on frontal sections in Figs. 7 and 8, at different anteroposterior levels of the thalamus. On these highresolution MRI, several thalamic and basal ganglia subdivisions can be well recognized: the striatum (PuT, Cd), both segments of the pallidum $(\mathrm{GPe} / \mathrm{GPi})$ separated by the internal medullary lamina (Fig. 8, A20-A15), medial, 


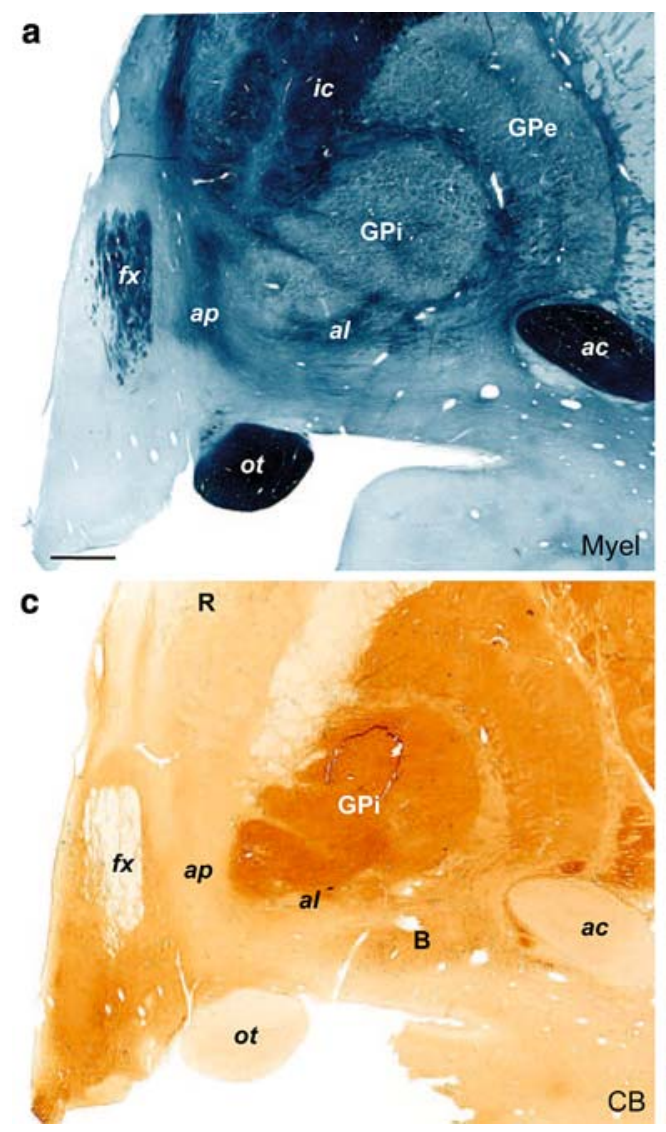

Fig. 10 Multiarchitectonic characteristics of the pallidal and subpallidal areas on photomicrographs of frontal sections stained for a myelin, $\mathbf{b} \mathrm{AChE}$ or $\mathbf{c}$ immunoreacted for $\mathrm{CB}$ and $\mathbf{d} \mathrm{CR}$. Note the clear contrast between al (only moderately stained) and the GPi (enhanced

lateral, and anterior thalamic nuclei (AV, LD, MD, LP, and the intralaminar CM and CL nuclei). The reticular nucleus $(\mathrm{R})$ is also distinguishable between the internal capsule and the lateral nuclei (Fig. 7, A5-A7.5). The fct tract is illustrated in Fig. 7 at three anteroposterior levels (A7.5, A5.0, and A2.5), highlighting its entrance into the thalamus. The course of the pallidothalamic fibres is shown in Fig. 8, from their emergence from the internal part of the pallidum (A20.0 and A17.5 for the al and A17.5 and A15.0 for the fl) up to their entry in the thalamus (A12.25). At levels A17.5 and A15.0, the course of the tract in the subthalamic area and the most medial extension of the al just before merging with the fl to form the $\mathrm{ft}$ are also clearly recognized. Other fibre tracts such as the fornix (fx), the mtt and the optic tract (ot) are strongly contrasted.

Stereotactic localization and interindividual variability

The stereotactic position of the cerebello- and pallidothalamic tracts was determined in six hemispheres (three brains; cases $\mathrm{Hb} 1, \mathrm{Hb} 4$, and $\mathrm{Hb} 5$; Table 1). As seen on
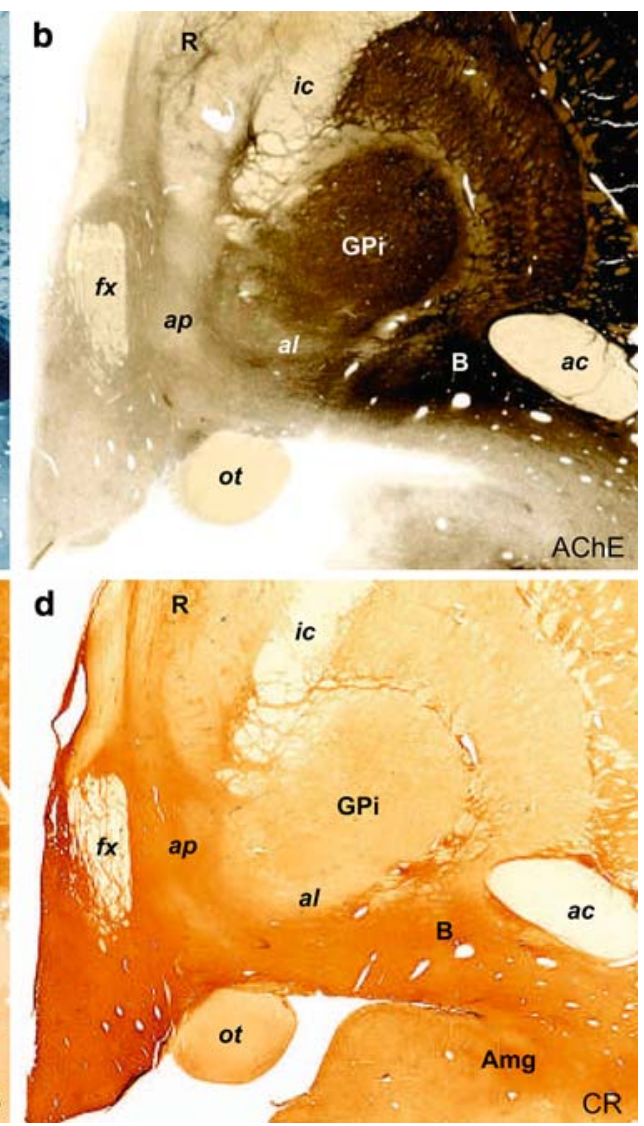

in $\mathrm{CB}, \mathbf{c}$ ), and the area underneath the pallidum (or sublenticular area, enhanced for $\mathrm{CR}$, d). A continuity between the sublenticular area and the ansa peduncularis (ap) is seen with CR immunostaining. Case Hb4. Scale bar: $3 \mathrm{~mm}$

sagittal and horizontal planes (Figs. 5, 6), the fct enters the thalamus more posterior and lateral than the $\mathrm{ft}$, but the two come into close proximity at several mediolateral levels (e.g. Fig. 5, L7.2-L9) and in horizontal planes, ventral to the intercommissural level (e.g. Fig. 6, level V0.9). Nevertheless, there is a gap between the two tracts, as best seen in sagittal sections stained for myelin or immunoreacted for PV (arrows in Fig. 3a, d) and the bulks of the fct and ft are clearly separated. The position of the two tracts in different brains is illustrated on sagittal and horizontal atlas sections in Fig. 12. The fct, $\mathrm{ft}$, and fl from two different brains ( $\mathrm{Hb} 1$ in red and $\mathrm{Hb} 4$ in gray) are compared on sagittal sections (L7 and L8) in upper panels. In these representations, the tracts show similar dorsoventral and anteroposterior positions. More variations are seen in the mediolateral axis, as best illustrated on horizontal section (lower panel) where the fiber tracts from four different brains $(\mathrm{Hb} 1, \mathrm{Hb} 2, \mathrm{Hb} 3$, and $\mathrm{Hb5}$ ) are superposed. The area of maximal overlap between three of the four cases (represented in yellow) is located in the medial more than the lateral part of the tracts. This is related to overall differences in mediolateral width of the thalamus and subthalamic area in the different brains 


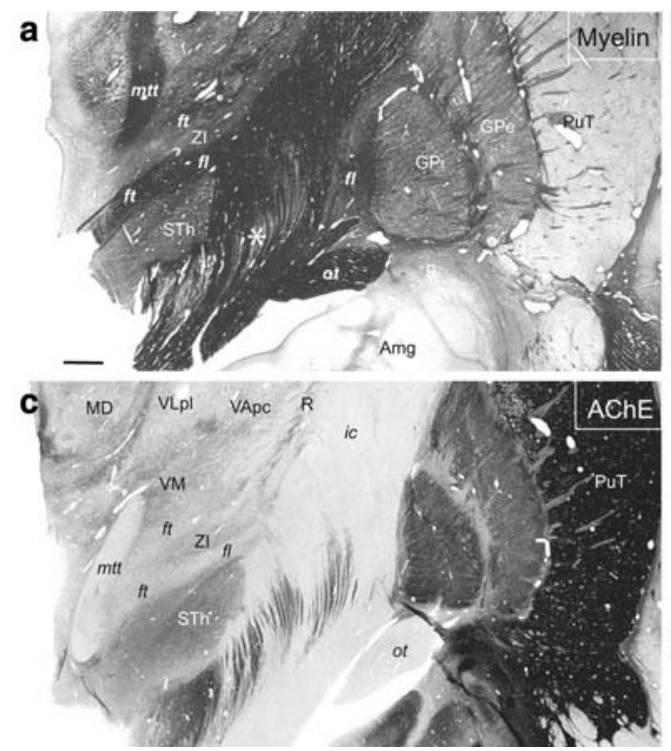

Fig. 11 Photomicrographs of adjacent frontal sections $15 \mathrm{~mm}$ anterior to the posterior commissure stained for a myelin, $\mathbf{c}$ AchE, and $\mathbf{b}$ immunostained for the calcium-binding proteins $\mathrm{CB}$ and $\mathbf{d} \mathrm{PV}$. Pallidothalamic fibres (fl, $\mathrm{ft}$ ) are darkly stained for myelin, moderately for AChE and PV, and negatively for CB. The STh, thalamic VLp nucleus and the optic tract (ot) are strongly enhanced in PV-ir. The

(as also reported in Morel 2007). As seen on sagittal planes (upper panels of Fig. 12), the dorsoventral variation of the position of the two tracts is similar to that of the ventral part of the thalamus (e.g. CM, VPMpc, and ventral limit of VLpv and VM), but much smaller than the variation of dorsal thalamic nuclei (e.g. LD, dorsal extent of VLpd, $\mathrm{MD}$, and $\mathrm{CL}$ ). In order to evaluate more quantitatively the variability of the cerebello- and pallidothalamic tracts, the mediolateral and anteroposterior stereotactic coordinates of the bulk centers of the two tracts were determined on sagittal planes of two different brains ( $\mathrm{Hb} 1$ and $\mathrm{Hb} 4)$. In every sagittal map, the anteroposterior coordinate of the center of the fibre bulks was measured at their intersecting point with the DV0, V1, and V2 horizontal planes, respectively. The mediolateral and anteroposterior coordinates of the $\mathrm{ft}$, $\mathrm{fl}$, and fct are plotted in Fig. 13 for the three dorsoventral levels.

The smallest anteroposterior distance between fct and $\mathrm{ft}$ centers is similar $(2.4 \mathrm{~mm})$ in both $\mathrm{Hb} 1$ and $\mathrm{Hb} 4$, when considering the three dorsoventral planes. At V2 level, the median anteroposterior value of $\mathrm{ft}$ is $11 \mathrm{~mm}$ in $\mathrm{Hb} 1$ and $12.7 \mathrm{~mm}$ in $\mathrm{Hb} 4$. In terms of mediolateral extension, there is a significant difference between the two cases with an extension from L4.5 to L9 for $\mathrm{Hb} 1$, and from L2 to L5 for $\mathrm{Hb} 4$. The position of the $\mathrm{fl}$ is more anterior to $\mathrm{ft}$ in both cases (median values of 15.6 and $15.2 \mathrm{~mm}$ anterior to pc for $\mathrm{Hb} 1$ and $\mathrm{Hb} 4$, respectively), and the mediolateral extension varies from 6.3 to $8.1 \mathrm{~mm}$ in case $\mathrm{Hb} 1$, and from 3 to $6 \mathrm{~mm}$ in case $\mathrm{Hb} 4$. For the fct, anteroposterior median

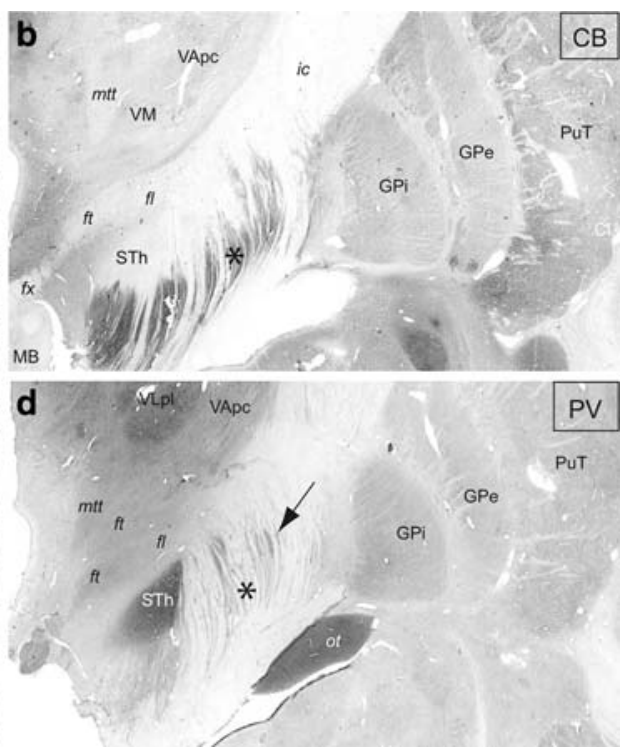

arrow in d points to presumed pallidosubthalamic fibres (fasciculus subthalamicus) crossing the posterior limb of the internal capsule. The asterisks in $\mathbf{a}, \mathbf{b}$, and $\mathbf{d}$ indicate matching locations in the internal capsule corresponding to striatonigral fibres which are strongly enhanced in CB-ir but unstained for myelin. Case Hb4. Scale bar (a): $2 \mathrm{~mm}$

value is $6.8 \mathrm{~mm}$ in $\mathrm{Hb} 1$ and $6.7 \mathrm{~mm}$ in $\mathrm{Hb} 4$. The mediolateral extension is from L4.5 to L14 in $\mathrm{Hb} 1$, and from $\mathrm{L} 2$ to L10 in $\mathrm{Hb} 4$. As already shown in Fig. 12, the variations of the tracts in the different cases are not homogeneous in the three planes, with smallest variations in anteroposterior and dorsoventral axes, and largest variations in mediolateral axis.

\section{Implications for stereotactic surgery}

According to the orientations and stereotactic positions of the cerebello- and pallidothalamic tracts (Figs. 5, 6, 12), and because of the electrode trajectory restrained by a precoronal approach, our surgical targeting in PD and in ET are determined at $2 \mathrm{~mm}$ ventral to intercommissural plane (V2). The anteroposterior and mediolateral coordinates for the pallidothalamic tractotomy (PTT) are at midcommissural $(\mathrm{mcl})$ level and $7 \mathrm{~mm}$ lateral to ventricular border, respectively. For the cerebellothalamic tractotomy (CTT), these are 5-6 $\mathrm{mm}$ posterior to $\mathrm{mcl}$ and $8 \mathrm{~mm}$ lateral to ventricular border, respectively. This strategy has been developed for (1) best inclusion of both fl and $\mathrm{ft}$ in PD, with minimum involvement of STh and keeping a safe distance between the RFL and the internal capsule and mtt (see also Aufenberg et al. 2005), and (2) to take the cerebellothalamic tract between $\mathrm{RN}$ and the thalamus, but avoid the risk of encroaching on the trigeminal thalamic relay VPM nucleus (more "eloquent" structure 

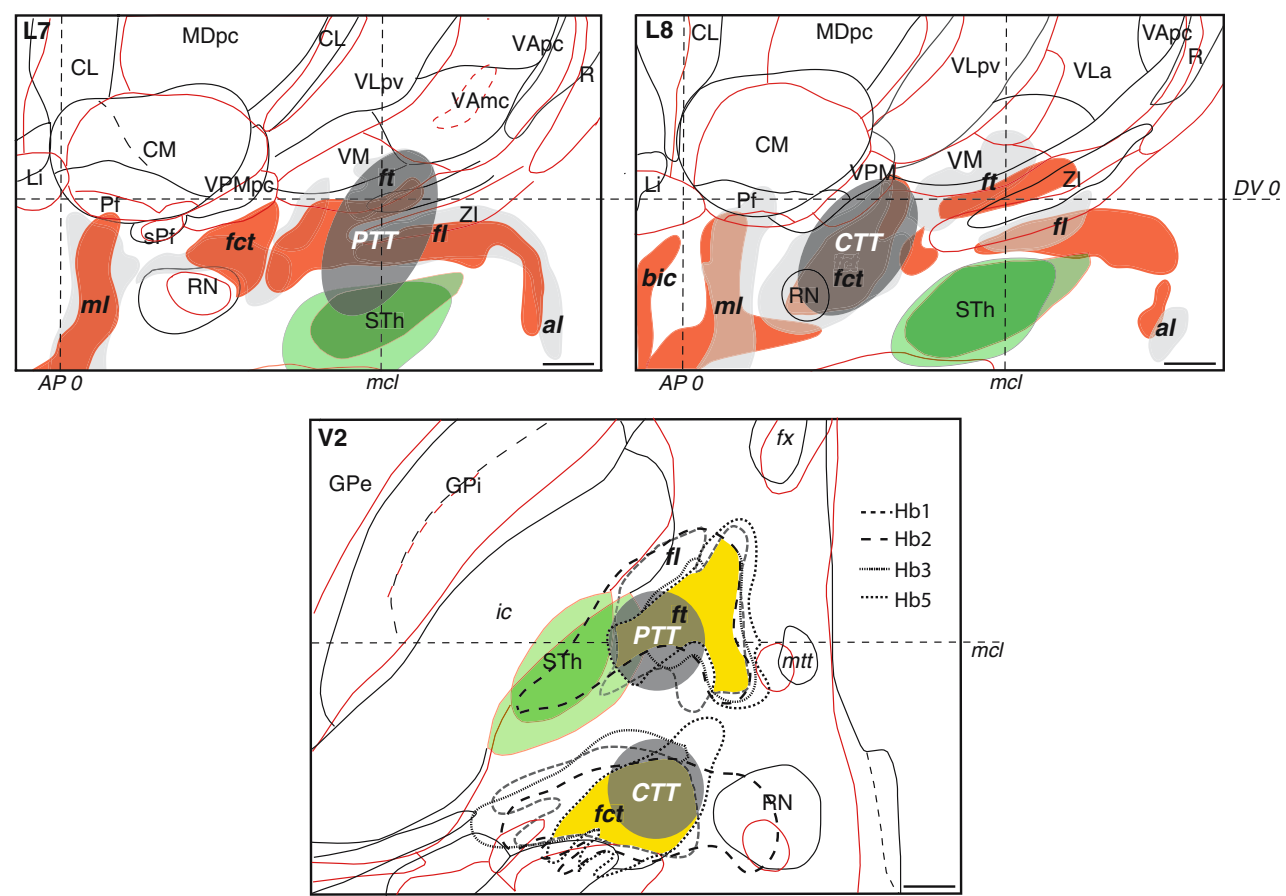

Fig. 12 Variability of the fibre tracts in the subthalamic area in sagittal (upper panels) and horizontal (lower panel) atlas maps of different brains. In sagittal sections (upper panels, L7 and L8), red contours and filling correspond to brain $\mathrm{Hb} 1$ and black contours and gray filling correspond to brain Hb4. In the horizontal section represented in lower panel, red and black thalamic and basal ganglia contours correspond to cases $\mathrm{Hb} 1$ and $\mathrm{Hb} 3$, respectively (see also Table 1). For reference, the STh is represented in green. In the horizontal section (lower panel), the delineation of $\mathrm{fct}$, $\mathrm{ft}$, and $\mathrm{fl}$ in four different cases is represented by different dotted lines and the area of maximal overlap between the tracts in $\mathrm{Hb} 1, \mathrm{Hb} 2$, and $\mathrm{Hb} 5$ is depicted in yellow. In all panels, the locations and sizes of the targeted PTT and CTT are represented in dark gray areas. Positions of the horizontal intercommissural (DV0), posterior commissural (AP0) and midcommissural $(\mathrm{mcl})$ planes are also indicated. Midcommissural level in the sagittal maps corresponds to that of case $\mathrm{Hb} 4(13 \mathrm{~mm})$. Scale bars: $2 \mathrm{~mm}$ than VPMpc) by remaining relatively medial. The locations of the targeted PTT and CTT in relation to the variability of the positions of the pallido- and cerebellothalamic tracts are represented in Fig. 12 on sagittal (upper panels) and horizontal (lower panel) atlas maps. The use of anteroposterior mcl level, instead of the pc level, and of physiological control for depth assessment, allows adjusting the site for RFL in different patients. For mediolateral coordinates, some correction can be made according to the width of the thalamus and subthalamic area assessed by the border of the internal capsule. However, corrections are minimized by the fact that targeting is directed at more medial portions of the two tracts where interindividual variations are less marked (Morel 2007; see also Fig. 12, lower panel). Figure 14 illustrates PTT of $\mathrm{fl}$ and $\mathrm{ft}$, and CTT of fct in two patients with PD and ET, respectively, on 2-day postoperative axial T1-weighted MRI (panels a and b) and projections onto a horizontal section of the atlas (panel c). The PD patient suffered from a tremor dominant unilateral form of the disease and at 1-year follow-up, benefited from a complete tremor relief, without arising of new symptoms. He experienced a strong improvement of his quality of life and daily activities. The ET patient manifested at the 1.5-year follow-up, a complete control of both the postural and kinetic components of his prominent action tremor.

\section{Discussion}

This study was designed to provide an anatomical basis for stereotactic targeting of the pallido- and cerebellothalamic fibre tracts in motor disorders, particularly in PD and ET. Indeed, there is an increasing evidence that RFL or DBS partially or completely involving subthalamic fibre tracts from the pallidum (in case of PD) or from the cerebellar nuclei (in case of ET or other types of kinetic tremors) to the thalamus are more efficient for relieving PD or ET symptoms than targets placed in the thalamus or STh (Voges et al. 2002; Zonenshayn et al. 2004; Breit et al. 2006; Godinho et al. 2006; Plaha et al. 2006; Hamel et al. 2007; Herzog et al. 2007a, b). Our surgical approach, which aims at directly interrupting the fibre tracts in subthalamic area with a RFL (Magnin et al. 2001a, b; 
Fig. 13 Spatial relationship between the fct, $\mathrm{ft}$, and fl. In each diagram, the $x$-axis represents the distance $(\mathrm{mm})$ to the posterior commissure and the $y$-axis, the distance to the medial thalamic border. The distances were measured at three different dorsoventral levels $[2 \mathrm{~mm}$ ventral (V2) and $1 \mathrm{~mm}$ ventral (V1) to intercommissural level, and intercommissural level (DV0)] of two different brains ( $\mathrm{Hb} 1$ and $\mathrm{Hb} 4)$ cut in the sagittal plane. For each dorsoventral level, the center of the bulk on the anteroposterior (A-P) axis was measured at medio-lateral (ML) levels between 0 (ventricular border) and $18 \mathrm{~mm}$
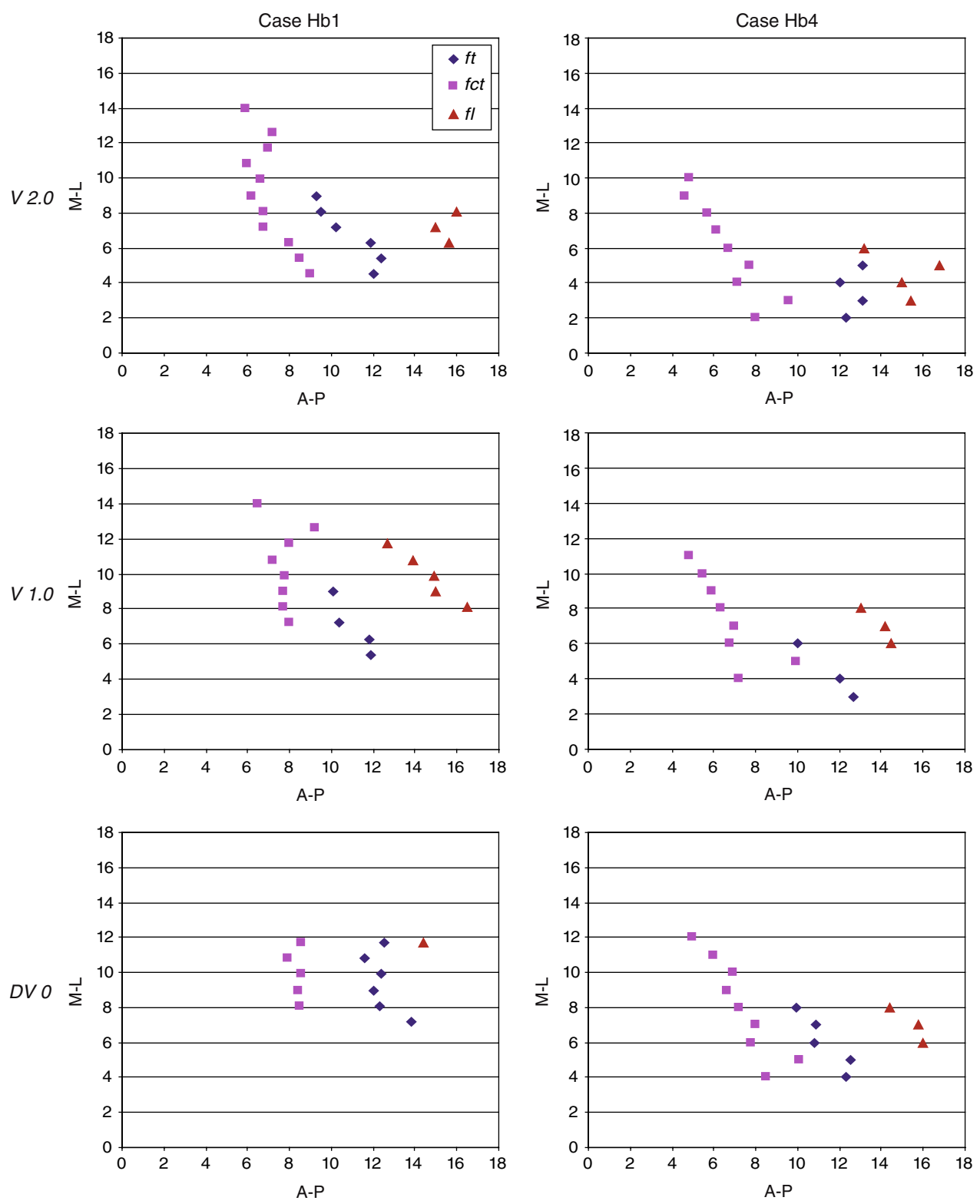

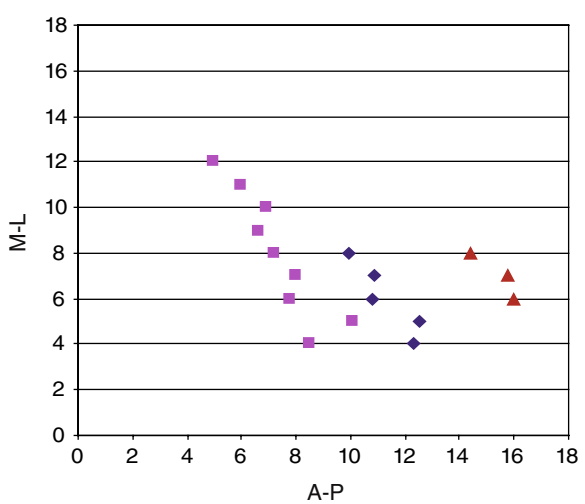

Aufenberg et al. 2005), is a re-actualisation of earlier surgical experiences (Spiegel and Wycis 1954; Spiegel et al. 1963; Mundinger 1965; Bertrand et al. 1973), although with limited technical support at the time. This approach offers the advantage over thalamic RFL (as used principally for tremor) to spare thalamic cells and related thalamocortical loops. Furthermore, with a relatively small lesion ( $\sim 4 \mathrm{~mm}$ diameter), the efferents from a large pallidal territory (in case of the PTT in PD) and afferents to relatively large thalamic territory (in case of the CTT in ET) can be interrupted and efficacy of the surgery significantly improved. Risks associated with thalamic (e.g. encroachment onto internal capsule when the lateral part of the nucleus is targeted) or pallidal (with the vicinity of the optic tract and internal capsule) surgery are also prevented by accurate targeting of the subthalamic area.
Methodological aspects

Our results are based on histologically processed sections of the human thalamus and basal ganglia and on correlations with post-mortem MRI. The myelin staining served as first basis for the identification of the fibre tracts, though with the following limitations: since the origin and terminal of the fibre tracts cannot be assessed in the present material (myelin stain, in normal brains), our identification relies on previous studies in humans, particularly those based on Marchi retrograde degeneration methods after lesions in the pallidum or cerebellar nuclei (Martinez 1961; Beck and Bignami 1968). These studies provide very valuable anatomical information and link to the clinic but cannot be used for stereotactic targeting. On the other hand, the most commonly used atlases of the human thalamus 
Fig. 14 Targeting in functional neurosurgery. a, b Postoperative T1-weighted axial MRI and c atlas reconstruction of pallidothalamic (PTT) and cerebellothalamic (CTT) tractotomies in two patients with PD and ET, respectively (see text for more detail). The horizontal atlas map is $1.8 \mathrm{~mm}$ ventral (V1.8) to the intercommissural plane. Scale bars: $5 \mathrm{~mm}$ in a and $\mathbf{b}, 2 \mathrm{~mm}$ in $\mathbf{c}$
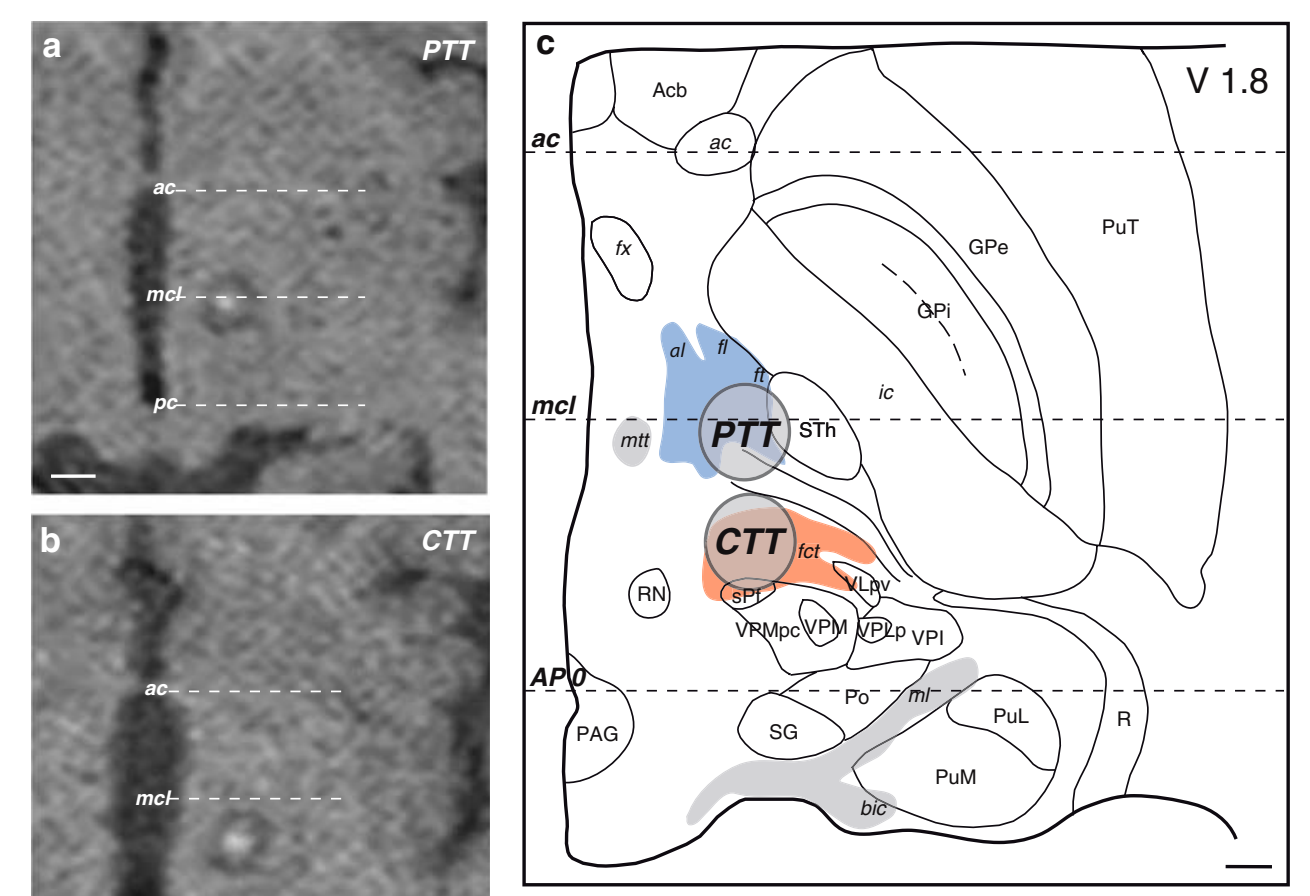

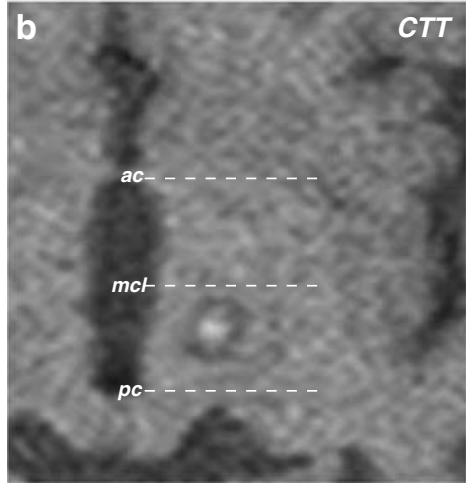

(Schaltenbrand and Bailey 1959; Schaltenbrand and Wahren 1977; Mai et al. 2004) provide a basis for coordinate determination of the tracts, though with low-spatial resolution and insufficient 3D stereotactic precision. In spite of these limitations, the reproducibility of our results in many cases and comparison with the existing data in human allow us to identify the main bulks of the fibre tracts with a certain confidence. Furthermore, the use of immunohistochemical staining procedures in addition to myelin and Nissl stainings, provide further criteria to ascertain the delimitations and discriminate between the different tracts. This was particularly the case for the passage of fibres through the internal capsule and cerebral peduncle, where identification of tracts can only be inferred, but not firmly assessed, on myelin stained sections. One critical problem with myelin stain, i.e. deformation and shrinkage due to alcohol pre-treatment in the myelin staining procedure could be partly corrected in a most recent case (Table 1, Hb5) by applying a protocol on mounted, instead of freefloating sections (Burgel et al. 1997). The delineations of the fibre bulks were also superposed on Nissl sections (where they appear negatively stained), which undergo minimal deformations and served as primary basis for map drawings in the Morel atlas. Moreover, high-resolution post-mortem MRI scans prior to guillotine section and histological processing, were very helpful not only to visualize the subthalamic fibre tracts and thalamic structures with no additional deformation (except that caused by removing the brain from the skull), but also to better assess

the positions of the reference stereotactic intercommissural plane and estimate the mediolateral extent of thalamic and subthalamic areas.

\section{Nomenclature}

The nomenclature of the subthalamic fibres was revised and adapted in an effort to combine old terminology with more recent studies in primates. Since Forel's seminal morphological studies of the pallidothalamic fibres (without knowing their origin) that were described as fields (or "Campi") (Forel 1877), the terms H, H1, and H2 fields of Forel have been consecutively used by different neuroanatomists. Initially, field $\mathrm{H} 1$ designated the dorsal extension of the fibres from $\mathrm{H}$ en route to the thalamus, and $\mathrm{H} 2$ the ventral continuity of $\mathrm{H}$ to the substantia innominata and the Pes Pedunculi. The origin of $\mathrm{H}$ field was supposed to be the red nucleus. Forel described those fibres with the idea of the logical sequence of $\mathrm{H}, \mathrm{H} 1$, and $\mathrm{H} 2$, but not knowing the relationship between the fibres coursing in his fields and the thalamus or the pallidum. He was not able to differentiate between cerebellothalamic fibres running in his $\mathrm{H}$ field (the so-called prerubral field of Forel) and the pallidothalamic (ft) fibres more anteriorly. By close examination of the illustrations in Forel's original paper (Forel 1877) and according to our data, we consider field $\mathrm{H}$ as comprising the posterior extension of the $\mathrm{ft}$ containing fibres from both the ansa lenticularis and the fasciculus 
lenticularis, and a part of the dorsal extension of the fct near its entry into the thalamus. Nevertheless, the definition of the $\mathrm{H}$ field as part of the pallidothalamic pathways is still used in the literature and often misleading. A continuity of the fibres from $\mathrm{H} 2$, to $\mathrm{H} 2+\mathrm{H} 1$, and $\mathrm{H} 1$ was first described by Cécile Vogt and Oskar Vogt (1920) and corresponds to the $\mathrm{fl}, \mathrm{fl} / \mathrm{al}$ mergence and the $\mathrm{ft}$ in our study. Other fibre degeneration studies in monkeys adopted this nomenclature (Vogt 1909; Ranson 1939; Nauta and Mehler 1966), changing also the names of the components of the ansa lenticularis of von Monakow (Von Monakow 1895; Nauta and Mehler 1966) to take into account their different projections, such as the STh for the middle component.

For the cerebellothalamic fibres, the choice of the term fasciculus cerebellothalamicus participates to the same effort to homogenize the nomenclature for subthalamic fibre tracts.

Pallidothalamic tract: origin of the al and fl

The origin of the pallidothalamic tract through al and $\mathrm{fl}$ from the internal segment of the globus pallidus has been confirmed by a number of studies in primates (Nauta and Mehler 1966; Kuo and Carpenter 1973; Inase and Tanji 1994; Parent and Hazrati 1995a; Sakai et al. 1996; Sidibe et al. 1997, 2002; Baron et al. 2001; Parent et al. 2001; Haber 2003; Parent and Parent 2004) but how the cells of origin of these two fibre systems distribute within the GPi is still controversial. On one hand, Parent and col. (Parent et al. 2001; Parent and Parent 2004), using single-axon tracing method propose a wide distribution of pallidofugal fibres through the al or fl, without particular anteroposterior or lateromedial segregation of their parent cells in GPi. Others using tracer injections or RFL lesions in GPi (Baron et al. 2001, 2006) put forward a different innervation by the al and $\mathrm{fl}$, with the $\mathrm{fl}$ originating principally from posterior (motor-related) and the al from anterior (non-motor related) GPi, in line with earlier model (Kuo and Carpenter 1973). The origin of the al and fl within the human GPi cannot be assessed in the present study, but we infer from the anteroposterior extent of the medial and ventral components of the fibres emerging from GPi that al comprises fibres originating from more anterior portions of the nucleus than the fl, although the al can also be followed relatively far posteriorly at the ventral edge of the GPi.

Course of al and $\mathrm{fl}$ in the subthalamic region

The merging together of the al and $\mathrm{fl}(\mathrm{H} 2)$ to form the $\mathrm{ft}$ (H1) in subthalamic area was first described by Vogt (1909). The exact location where the fl and al meet together, becoming $\mathrm{ft}$, could not be determined with our methods, but the data suggest that the two tracts merge in the dorsal part of the $\mathrm{H} 1+\mathrm{H} 2$ field of Forel, about $2.5 \mathrm{~mm}$ ventral to the DV0 plane and about $2 \mathrm{~mm}$ posterior to mcl level.

The thalamic projections of the $\mathrm{ft}$, based on studies in monkeys, distribute principally to VApc and VLa, but also VLp, VM and the centre médian-parafascicular (CM-Pf) complex (Nauta and Mehler 1966; Kuo and Carpenter 1973; Parent and De Bellefeuille 1983; Percheron et al. 1993; Inase and Tanji 1994, 1995; Rouiller et al. 1994; Parent and Hazrati 1995a; Sakai et al. 1996, 1999, 2000; Sidibe et al. 1997; Haber and McFarland 2001; Parent and Parent 2004). They overlap to some extent with terminals of the fct in VLp and VLa (Ilinsky and Kultas-Ilinsky 1987; Rouiller et al. 1994; Sakai et al. 1996), though direct convergence of the pallido- and cerebellothalamic pathways onto thalamocortical neurons appears very rare, as also demonstrated physiologically (Yamamoto et al. 1983; Anderson and Turner 1991). The VLa, Vapc, and VM are likely to be also primary targets of the $\mathrm{ft}$ in the human brain, as indicated by the course of the tract, particularly on sagittal sections (e.g. Fig. 5). Furthermore, in spite of the fact that the $\mathrm{ft}$ is negatively stained for CB (see Fig. 11b), the VLa and VApc show enhanced immunostaining (Figs. 4b, 11b; Morel 2007) and pallidothalamic terminals have been reported to be confined to the CB-positive territory of the motor thalamus in monkeys (see Percheron et al. 1996; Parent et al. 2001; also suggested by Calzavara et al. 2005). In terms of functional aspects related to the fibres coursing along al and $\mathrm{fl}$ in the human subthalamic area, our surgical experience revealed that in a PD patient, a partial PTT due to lateral shift of the electrode that left the medial part of the ft (most probably containing mainly fibres of the al) intact, resulted in only partial relief of the motor symptoms. A second, complementary surgical intervention with a medially placed RFL resulted in complete relief (unpublished observation). This clinical observation would agree with the scheme proposed by Parent and colleagues (Parent and Parent 2004), where motor fibres course through both fl and al, more than with that of Baron et al. (Baron et al. 2006), where those fibres are mainly restricted to the fl.

Other subthalamic fibre tracts related to basal ganglia efferent pathways

Two fibre systems apart from the pallidothalamic tracts could be recognized on the basis of immunohistochemical stainings. The first is related to $\mathrm{CB}$ positive fibres running through the pallidal segments, the internal capsule and penetrating the cerebral peduncle on the ventral aspect of 
the STh "en route" to the substantia nigra, pars reticulata. The latter is also enhanced in CB-ir and is known to receive important projections from the striatum (putamen and caudate) (Lynd-Balta and Haber 1994; Haber et al. 1995; Parent and Hazrati 1995a; Levesque and Parent 2005). These striatonigral fibres were already described in terms of neurochemical characteristics in a previous report on the human basal ganglia (Morel et al. 2002). A second fibre tract could be recognized at the anterior, mid-dorsal, and lateral aspect of the STh nucleus, both characterized by enhanced PV-ir. Although the course of the fibres could not be followed back to the pallidum, their position between the $\mathrm{fl}$ and the al strongly suggests that they belong to the fasciculus subthalamicus, or middle division of von Monakow's ansa lenticularis (Von Monakow 1895; Nauta and Mehler 1966) which connects the external globus pallidus (GPe) with the STh (Ranson 1939; Nauta and Mehler 1966; Parent and Hazrati 1995b; Shink et al. 1996). Indeed, dense degenerated fibres were observed in this part of the tract and in the STh after lesion of GPe in human (Morel et al. 2001). Some fibres coursing on the dorsal aspect of the STh and continuous with the fl tract (e.g. Fig. 4b) may correspond to efferents from the GPi to the pedonculopontine nucleus (PPN) (Nauta and Mehler 1966; Shink et al. 1997; Parent et al. 2001; Parent and Parent 2004). These pallidopedunculopontine connections are supposed to be affected by medial pallidotomies in PD patients and could explain part of the beneficial results against akinesia. These would likely be also interrupted by the PTT and possibly, though only partially, by subthalamic DBS or RFL (targets too far anterior and lateral).

Previous experiments in monkey have shown that $\mathrm{SNr}$ projects to the thalamus, particularly to VAmc, VM, MDpl, and Pf nuclei (Carpenter et al. 1976; Parent and De Bellefeuille 1983; Francois et al. 1984, 2002; Ilinsky et al. 1993; Percheron et al. 1996). Thalamic projections of the $\mathrm{SNr}$ share some territories with those from the GPi (e.g. VM), but others are different (e.g. VAmc) (Ilinsky et al. 1993). Nigral projections to the thalamus were not described in humans but by comparison with data gathered in monkeys, we can infer that they probably course along the posterior part of the ft. These would also be interrupted by the PTT, in contrast to pallidotomies or subthalamic DBS or RFL, the latter affecting only the fl.

\section{Cerebellothalamic tract}

Auguste Forel already described fibres originating in the dentate nucleus and passing through and lateral to the red nucleus ("Bindearm") before entering the thalamus. The first experimental anterograde study of the cerebellothalamic fibres after destruction of the dentate nucleus in monkey is due to Vogt (Vogt 1909). She described projections to the thalamus, in particular to its ventral lateral part. The origin of the cerebellothalamic fibres in the cerebellar nuclei (dentate, interposed, and fastigial nuclei) and its projections to the thalamus are now well established. Anterograde studies in monkeys have shown that after tracer injections in cerebellar nuclei, terminal labels are found primarily in VLp, in discrete zones of VLa and in the intralaminar CM/Pf and CL nuclei (Asanuma et al. 1983a, b; Jones 1990; Percheron et al. 1993; Rouiller et al. 1994; Sakai et al. 1996; Calzavara et al. 2005). Our observations that the bulk of the fct is mainly directed toward the VLp, which is enhanced in PV-ir (see also Fig. 3d), are consistent with reports in monkeys although with indirect demonstration (Calzavara et al. 2005). We cannot exclude however that the fct also innervates the VLa, as suggested in sagittal sections where some fibres ascend toward the VLa through a more anterior part of the VM. Although some overlap exists between the cerebello- and pallidothalamic terminals fields in the lateral thalamus, direct interaction between the two seems very limited, as discussed above. For the medial thalamus, we noticed that some fibres emerging from the $\mathrm{RN}$ and most probably associated with the fct, take a turn medially toward the CM and possibly CL nuclei. This may well correspond to the medial cerebellothalamic component directed to the intralaminar nuclei described by others (Asanuma et al. 1983a, b; Rouiller et al. 1994; Sakai et al. 1996; Calzavara et al. 2005).

Relations between cerebello- and pallidothalamic fibres in the subthalamic region: consequences for neurosurgical targeting

The present study demonstrates that the pallidothalamic and cerebellothalamic tracts do not to converge in the subthalamic region. We cannot exclude some fibre exchanges between the two tracts, but we can demonstrate that the main bulks are clearly separated. Immunohistochemical stainings, especially PV immunoreactivity and AChE, provided additional evidence for a separation between the two tracts. At thalamic level, evidence for a convergence of pallidal and cerebellar fibres onto the same nuclei, although with minor overlap, has been brought by experimental studies in monkeys (Rouiller et al. 1994; Sakai et al. 1996, 1999, 2000).

The demonstration at subthalamic level of a separation between cerebello- and pallidothalamic fibres is of major interest for functional neurosurgery. Being able to target a fibre bundle while sparing the other is particularly relevant for the surgical treatments of motor disorders with different underlying pathophysiology, such as PD and ET. The 
three-dimensional coordinates of the fct and ft determined in the present study allow placing RFL to selectively interrupt one or the other tract, as shown in Figs. 12 and 14. The most commonly used surgical approach for PD is to target the subthalamic nucleus with DBS. In the last few years, increasing evidence for more effectiveness of the stimulation sites at the dorsal border of the STh, rather than within the nucleus, has been reported (Voges et al. 2002; McIntyre et al. 2004; Zonenshayn et al. 2004; Breit et al. 2006; Godinho et al. 2006; Miocinovic et al. 2006; Butson et al. 2007). This indicates that the effect is at least partially due to involvement of the fibres from the fl (or $\mathrm{H} 2$ field of Forel) coursing over the dorsal border of the nucleus, on their way to join the al to finally form the ft. Similar evidence for the importance of the fibres in DBS efficacy was proposed by Benabid and col. (Benabid et al. 1996) using DBS of the VLp (or VIM) against tremor. They suggest that at the frequency most optimal for tremor suppression, the fibres (probably from the fct), rather than the thalamic cells, are affected. All these observations point to the fact that in the near future, the fibre tracts may well regain importance for the surgical treatment of motor disorders.

Acknowledgments We thank V. Streit for her skilful histological work, S. Kolias and M. Wyss for post-mortem MR scanning; and A. Aguzzi and H.-P. Lipp for providing autopsy material. This study was supported by the Swiss National Science Foundation (grants No. 3147238.96, 31-54179.98; 31-68248.02).

Open Access This article is distributed under the terms of the Creative Commons Attribution Noncommercial License which permits any noncommercial use, distribution, and reproduction in any medium, provided the original author(s) and source are credited.

\section{References}

Alheid GF (2003) Extended amygdala and basal forebrain. Annu NY Acad Sci 985:185-205

Alvarez L, Macias R, Lopez G, Alvarez E, Pavon N, Rodriguez-Oroz MC, Juncos JL, Maragoto C, Guridi J, Litvan I, Tolosa ES, Koller W, Vitek J, DeLong MR, Obeso JA (2005) Bilateral subthalamotomy in Parkinson's disease: initial and long-term response. Brain 128:570-583

Anderson ME, Turner RS (1991) Activity of neurons in cerebellarreceiving and pallidal-receiving areas of the thalamus of the behaving monkey. J Neurophysiol 66:879-893

Asanuma C, Thach WR, Jones EG (1983a) Anatomical evidence for segregated focal groupings of efferent cells and their terminal ramifications in the cerebellothalamic pathway of the monkey. Brain Res 286:267-297

Asanuma C, Thach WT, Jones EG (1983b) Distribution of cerebellar terminations and their relation to other afferent terminations in the ventral lateral thalamic region of the monkey. Brain Res 286:237-265

Aufenberg C, Sarnthein J, Morel A, Rousson V, Gallay M, Jeanmonod D (2005) A revival of Spiegel's campotomy: long term results of the stereotactic pallidothalamic tractotomy against the parkinsonian thalamocortical dysrhythmia. Thalamus Relat Syst 3:121-132

Baron MS, Sidibe M, DeLong MR, Smith Y (2001) Course of motor and associative pallidothalamic projections in monkeys. J Comp Neurol 429:490-501

Baron MS, Noonan JB, Mewes K (2006) Restricted ablative lesions in motor portions of GPi in primates produce extensive loss of motor-related neurons and degeneration of the lenticular fasciculus. Exp Neurol 202(1):67-75

Beck E, Bignami A (1968) Some neuro-anatomical observations in cases with stereotactic lessions for the relief of parkinsonism. Brain 91:589-618

Benabid AL, Pollak P, Gao D, Hoffmann D, Limousin P, Gay E, Payen I, Benazzouz A (1996) Chronic electrical stimulation of the ventralis intermedius nucleus of the thalamus as a treatment of movement disorders. J Neurosurg 84:203-214

Bertrand C, Martinez SN, Hardy J, Molina-Negro P, Velasco F (1973) Stereotactic surgery for Parkinsonism. Progr Neurol Surg 5:79112

Breit S, LeBas JF, Koudsie A, Schulz J, Benazzouz A, Pollak P, Benabid AL (2006) Pretargeting for the implantation of stimulation electrodes into the subthalamic nucleus: a comparative study of magnetic resonance imaging and ventriculography. Neurosurgery 58:ONS83-ONS95

Burgel U, Mecklenburg I, Blohm U, Zilles K (1997) Histological visualization of long fiber tracts in the white matter of adult human brains. J Hirnforsch 38:397-404

Butson CR, Cooper SE, Henderson JM, McIntyre CC (2007) Patientspecific analysis of the volume of tissue activated during deep brain stimulation. Neuroimage 34:661-670

Calzavara R, Zappala A, Rozzi S, Matelli M, Luppino G (2005) Neurochemical characterization of the cerebellar-recipient motor thalamic territory in the macaque monkey. Eur $\mathrm{J}$ Neurosci 21:1869-1894

Carpenter MB, Nakano K, Kim R (1976) Nigrothalamic projections in the monkey demonstrated by autoradiographic technics. J Comp Neurol 165:401-415

DeLong MR (1990) Primate models of movement disorders of basal ganglia origin. Trends Neurosci 13:281-285

Evers P, Uylings HB (1994) Effects of microwave pretreatment on immunocytochemical staining of vibratome sections and tissue blocks of human cerebral cortex stored in formaldehyde fixative for long periods. J Neurosci Methods 55:163-172

Forel A (1877) Untersuchungen über die Haubenregion und ihre oberen Verknüpfungen im Gehirn des Menschen und einiger Säugethiere, mit Beiträgen zu den Methoden des Gehirnuntersuchung. Arch Psychiatr Nervenkr 7:393-495

Francois C, Percheron G, Yelnik J (1984) Localization of nigrostriatal, nigrothalamic and nigrotectal neurons in ventricular coordinates in macaques. Neuroscience 13:61-76

Francois C, Yelnik J, Percheron G, Fenelon G (1994) Topographic distribution of the axonal endings from the sensorimotor and associative striatum in the macaque pallidum and substantia nigra. Exp Brain Res 102:305-318

Francois C, Tande D, Yelnik J, Hirsch EC (2002) Distribution and morphology of nigral axons projecting to the thalamus in primates. J Comp Neurol 447:249-260

Garonzik IM, Hua SE, Ohara S, Lenz FA (2002) Intraoperative microelectrode and semi-microelectrode recording during the physiological localization of the thalamic nucleus ventral intermediate. Mov Disord 17(Suppl 3):S135-S144

Godinho F, Thobois S, Magnin M, Guenot M, Polo G, Benatru I, Xie J, Salvetti A, Garcia-Larrea L, Broussolle E, Mertens P (2006) Subthalamic nucleus stimulation in Parkinson's disease : anatomical and electrophysiological localization of active contacts. J Neurol 253:1347-1355 
Gross RE, Lombardi WJ, Lang AE, Duff J, Hutchison WD, Saint-Cyr JA, Tasker RR, Lozano AM (1999) Relationship of lesion location to clinical outcome following microelectrode-guided pallidotomy for Parkinson's disease. Brain 122(Pt 3):405-416

Haber SN (2003) The primate basal ganglia: parallel and integrative networks. J Chem Neuroanat 26:317-330

Haber S, McFarland NR (2001) The place of the thalamus in frontal cortical-basal ganglia circuits. Neuroscientist 7:315-324

Haber SN, Kunishio K, Mizobuchi M, Lynd-Balta E (1995) The orbital and medial prefrontal circuit through the primate basal ganglia. J Neurosci 15:4851-4867

Hamel W, Fietzek U, Morsnowski A, Schrader B, Herzog J, Weinert D, Pfister G, Muller D, Volkmann J, Deuschl G, Mehdorn HM (2003) Deep brain stimulation of the subthalamic nucleus in Parkinson's disease: evaluation of active electrode contacts. J Neurol Neurosurg Psychiatry 74:1036-1046

Hamel W, Herzog J, Kopper F, Pinsker M, Weinert D, Muller D, Krack P, Deuschl G, Mehdorn HM (2007) Deep brain stimulation in the subthalamic area is more effective than nucleus ventralis intermedius stimulation for bilateral intention tremor. Acta Neurochir (Wien) 149:749-758

Hassler R (1982) Architectonic organization of the thalamic nuclei. In: Schaltenbrand G, Walker AE (eds) Stereotaxy of the human brain. Anatomical, physiological and clinical applications. G. Thieme, Stuttgart, pp 140-180

Heimer L, Harlan RE, Alheid GF, Garcia MM, de Olmos J (1997) Substantia innominata: a notion which impedes clinical-anatomical correlations in neuropsychiatric disorders. Neuroscience 76:957-1006

Herzog J, Pinsker M, Wasner M, Steigerwald F, Wailke S, Deuschl G, Volkmann J (2007a) Stimulation of subthalamic fibre tracts reduces dyskinesias in STN-DBS. Mov Disord 22:679-684

Herzog J, Hamel W, Wenzelburger R, Potter M, Pinsker MO, Bartussek J, Morsnowski A, Steigerwald F, Deuschl G, Volkmann J (2007b) Kinematic analysis of thalamic versus subthalamic neurostimulation in postural and intention tremor. Brain 130:1608-1625

Hutchins B, Weber JT (1983) A rapid myelin stain for frozen sections: modification of the Heidenhain procedure. J Neurosci Methods 7:289-294

Hutchison WD, Allan RJ, Opitz H, Levy R, Dostrovsky JO, Lang AE, Lozano AM (1998) Neurophysiological identification of the subthalamic nucleus in surgery for Parkinson's disease. Ann Neurol 44:622-628

Ilinsky IA, Kultas-Ilinsky K (1987) Sagittal cytoarchitectonic maps of the Macaca mulatta thalamus with a revised nomenclature of the motor-related nuclei validated by observations on their connectivity. J Comp Neurol 262:331-364

Ilinsky IA, Jouandet ML, Goldman-Rakic PS (1985) Organization of the nigrothalamocortical system in the rhesus monkey. J Comp Neurol 236:315-330

Ilinsky IA, Tourtellotte WG, Kultas-Ilinsky K (1993) Anatomical distinctions between the two basal ganglia afferent territories in the primate motor thalamus. Stereotact Funct Neurosurg 60:6269

Inase M, Tanji J (1994) Projections from the globus pallidus to the thalamic areas projecting to the dorsal area 6 of the macaque monkey: a multiple tracing study. Neurosci Lett 180:135-137

Inase M, Tanji J (1995) Thalamic distribution of projection neurons to the primary motor cortex relative to afferent terminal fields from the globus pallidus in the macaque monkey. J Comp Neurol 353:415-426

Jeanmonod D, Magnin M, Morel A (1996) Low-threshold calcium spike bursts in the human thalamus. Common physiopathology for sensory, motor and limbic positive symptoms. Brain 119(Pt 2):363-375
Jones EG (1990) Correlation and revised nomenclature of ventral nuclei in the thalamus of human and monkey. Stereotact Funct Neurosurg 54-55:1-20

Karachi C, Francois C, Parain K, Bardinet E, Tande D, Hirsch E, Yelnik J (2002) Three-dimensional cartography of functional territories in the human striatopallidal complex by using calbindin immunoreactivity. J Comp Neurol 450:122-134

Kobayashi K, Katayama Y, Kasai M, Oshima H, Fukaya C, Yamamoto T (2003) Localization of thalamic cells with tremor-frequency activity in Parkinson's disease and essential tremor. Acta Neurochir Suppl 87:137-139

Kuo JS, Carpenter MB (1973) Organization of pallidothalamic projections in the rhesus monkey. J Comp Neurol 151:201-236

Lenz FA, Kwan HC, Martin RL, Tasker RR, Dostrovsky JO, Lenz YE (1994) Single unit analysis of the human ventral thalamic nuclear group. Tremor-related activity in functionally identified cells. Brain 117(Pt 3):531-543

Levesque M, Parent A (2005) The striatofugal fiber system in primates: a reevaluation of its organization based on single-axon tracing studies. Proc Natl Acad Sci USA 102:11888-11893

Lozano AM, Lang AE, Hutchison WD, Dostrovsky JO (1997) Microelectrode recording-guided posteroventral pallidotomy in patients with Parkinson's disease. Adv Neurol 74:167-174

Lynd-Balta E, Haber SN (1994) Primate striatonigral projections: a comparison of the sensorimotor-related striatum and the ventral striatum. J Comp Neurol 345:562-578

Magnin M, Morel A, Jeanmonod D (2000) Single-unit analysis of the pallidum, thalamus and subthalamic nucleus in parkinsonian patients. Neuroscience 96:549-564

Magnin M, Jeanmonod D, Morel A, Siegemund M (2001a) Surgical control of the human thalamocortical dysrhythmia: II. Pallidothalamic tractotomy in Parkinson's disease. Thalamus Relat Syst $1: 81-89$

Magnin M, Jetzer U, Morel A, Jeanmonod D (2001b) Microelectrode recording and macrostimulation in thalamic and subthalamic MRI guided stereotactic surgery. Neurophysiol Clin 31:230-238

Mai JK, Assheuer J, Paxinos G (2004) Atlas of the human brain, 2nd edn. Elsevier, San Diego

Martinez A (1961) Fiber connections of the globus pallidus in man. J Comp Neurol 117:37-41

Matelli M, Luppino G (1996) Thalamic input to mesial and superior area 6 in the macaque monkey. J Comp Neurol 372:59-87

McIntyre CC, Savasta M, Walter BL, Vitek JL (2004) How does deep brain stimulation work? Present understanding and future questions. J Clin Neurophysiol 21:40-50

Mesulam MM (1982) Principles of horseradish peroxidase neurochemistry and their applications for tracing neural pathwaysaxonal transport, enzyme hsitochemistry and light microscopic analysis. In: Mesulam MM (ed) Tracing neruonal connections with horseradish peroxidase. Wiley, Chichester, pp 1-152

Middleton FA, Strick PL (2000) Basal ganglia and cerebellar loops: motor and cognitive circuits. Brain Res Brain Res Rev 31:236250

Miocinovic S, Parent M, Butson CR, Hahn PJ, Russo GS, Vitek JL, McIntyre CC (2006) Computational analysis of subthalamic nucleus and lenticular fasciculus activation during therapeutic deep brain stimulation. J Neurophysiol 96:1569-1580

Morel A (2007) Stereotactic atlas of the human thalamus and basal ganglia. Informa Healthcare, New York

Morel A, Magnin M, Jeanmonod D (1997) Multiarchitectonic and stereotactic atlas of the human thalamus. J Comp Neurol 387:588-630

Morel A, Magnin M, Jeanmonod D (2001) Efferent connections of the human striatum and pallidum: a nauta degeneration study. In: Kultas-Ilinsky K, Ilinsky I (eds) Basal ganglia and thalamus in health and disease. Kluwer, New York, pp 61-65 
Morel A, Loup F, Magnin M, Jeanmonod D (2002) Neurochemical organization of the human basal ganglia: anatomofunctional territories defined by the distributions of calcium-binding proteins and SMI-32. J Comp Neurol 443:86-103

Mundinger F (1965) Stereotaxic interventions on the zona incerta area for treatment of extrapyramidal motor disturbances and their results. Confin Neurol 26:222-230

Nauta WJ, Mehler WR (1966) Projections of the lentiform nucleus in the monkey. Brain Res 1:3-42

Obeso JA, Rodriguez-Oroz MC, Rodriguez M, Lanciego JL, Artieda J, Gonzalo N, Olanow CW (2000) Pathophysiology of the basal ganglia in Parkinson's disease. Trends Neurosci 23:S8-S19

Parent A, De Bellefeuille L (1983) The pallidointralaminar and pallidonigral projections in primate as studied by retrograde double-labeling method. Brain Res 278:11-27

Parent A, Hazrati LN (1995a) Functional anatomy of the basal ganglia. I. The cortico-basal ganglia-thalamo-cortical loop. Brain Res Brain Res Rev 20:91-127

Parent A, Hazrati LN (1995b) Functional anatomy of the basal ganglia. II. The place of subthalamic nucleus and external pallidum in basal ganglia circuitry. Brain Res Brain Res Rev 20:128-154

Parent M, Parent A (2004) The pallidofugal motor fiber system in primates. Parkinsonism Relat Disord 10:203-211

Parent M, Levesque M, Parent A (2001) Two types of projection neurons in the internal pallidum of primates: single-axon tracing and three-dimensional reconstruction. J Comp Neurol 439:162175

Percheron G, Francois C, Talbi B, Meder JF, Fenelon G, Yelnik J (1993) The primate motor thalamus analysed with reference to subcortical afferent territories. Stereotact Funct Neurosurg 60:32-41

Percheron G, Francois C, Talbi B, Yelnik J, Fenelon G (1996) The primate motor thalamus. Brain Res Brain Res Rev 22:93-181

Plaha P, Ben-Shlomo Y, Patel NK, Gill SS (2006) Stimulation of the caudal zona incerta is superior to stimulation of the subthalamic nucleus in improving contralateral parkinsonism. Brain 129:1732-1747

Ranson SW, Ranson M (1939) Pallidofugal fibers in the monkey. AMA Arch Neurol Psychiatr 42:1059-1067

Rouiller EM, Liang F, Babalian A, Moret V, Wiesendanger M (1994) Cerebellothalamocortical and pallidothalamocortical projections to the primary and supplementary motor cortical areas: a multiple tracing study in macaque monkeys. J Comp Neurol 345:185-213

Sakai ST, Inase M, Tanji J (1996) Comparison of cerebellothalamic and pallidothalamic projections in the monkey (Macaca fuscata): a double anterograde labeling study. J Comp Neurol 368:215228

Sakai ST, Inase M, Tanji J (1999) Pallidal and cerebellar inputs to thalamocortical neurons projecting to the supplementary motor area in Macaca fuscata: a triple-labeling light microscopic study. Anat Embryol (Berl) 199:9-19

Sakai ST, Stepniewska I, Qi HX, Kaas JH (2000) Pallidal and cerebellar afferents to pre-supplementary motor area thalamocortical neurons in the owl monkey: a multiple labeling study. J Comp Neurol 417:164-180

Schaltenbrand G, Bailey P (1959) Introduction to stereotaxis with an atlas of the human brain. Thieme, Stuttgart
Schaltenbrand G, Wahren W (1977) Atlas for stereotaxy of the human brain. Thieme, Stuttgart

Shink E, Bevan MD, Bolam JP, Smith Y (1996) The subthalamic nucleus and the external pallidum: two tightly interconnected structures that control the output of the basal ganglia in the monkey. Neuroscience 73:335-357

Shink E, Sidibe M, Smith Y (1997) Efferent connections of the internal globus pallidus in the squirrel monkey: II. Topography and synaptic organization of pallidal efferents to the pedunculopontine nucleus. J Comp Neurol 382:348-363

Sidibe M, Bevan MD, Bolam JP, Smith Y (1997) Efferent connections of the internal globus pallidus in the squirrel monkey: I. Topography and synaptic organization of the pallidothalamic projection. J Comp Neurol 382:323-347

Sidibe M, Pare JF, Smith Y (2002) Nigral and pallidal inputs to functionally segregated thalamostriatal neurons in the centromedian/parafascicular intralaminar nuclear complex in monkey. J Comp Neurol 447:286-299

Spiegel EA, Wycis HT (1954) Ansotomy in paralysis agitans. AMA Arch Neurol Psychiatry 71:598-614

Spiegel EA, Wycis HT, Szekely EG, Adams DJ, Flanagan M, Baird HW 3rd (1963) Campotomy in various extrapyramidal disorders. J Neurosurg 20:871-884

Velasco FC, Molina-Negro P, Bertrand C, Hardy J (1972) Further definition of the subthalamic target for arrest of tremor. J Neurosurg 36:184-191

Vitek JL, Bakay RA, Hashimoto T, Kaneoke Y, Mewes K, Zhang JY, Rye D, Starr P, Baron M, Turner R, DeLong MR (1998) Microelectrode-guided pallidotomy: technical approach and its application in medically intractable Parkinson's disease. J Neurosurg 88:1027-1043

Voges J, Volkmann J, Allert N, Lehrke R, Koulousakis A, Freund HJ, Sturm V (2002) Bilateral high-frequency stimulation in the subthalamic nucleus for the treatment of Parkinson disease: correlation of therapeutic effect with anatomical electrode position. J Neurosurg 96:269-279

Vogt C (1909) La myéloarchitecture du thalamus du cercopithèque. J Psychol Neur (Lpz) 12:285-324

Vogt C, Vogt O (1920) Zur Lehre der Erkrankungen des striären systems. J Psychol Neurol (Lpz) 25:627-846

Von Monakow C (1895) Experimentelle und pathologische-anatomische Untersuchungen über die Haubenregion, den Sehhügel und die Regio subthalamica, nebst Beiträgen zur Kenntnis früh erworbener Gross- und Kleinhirndefekte. Arch Psychiatr Nervenkr 27:1-128

Wichmann T, DeLong MR (2003) Pathophysiology of Parkinson's disease: the MPTP primate model of the human disorder. Annu NY Acad Sci 991:199-213

Yamamoto T, Hassler R, Huber C, Wagner A, Sasaki K (1983) Electrophysiological studies on the pallido- and cerebellothalamic projections in squirrel monkeys. Exp Brain Res 51:77-87

Zonenshayn M, Rezai AR, Mogilner AY, Beric A, Sterio D, Kelly PJ (2000) Comparison of anatomic and neurophysiological methods for subthalamic nucleus targeting. Neurosurgery 47:282-292; discussion 292-284

Zonenshayn M, Sterio D, Kelly PJ, Rezai AR, Beric A (2004) Location of the active contact within the subthalamic nucleus (STN) in the treatment of idiopathic Parkinson's disease. Surg Neurol 62:216-225; discussion 225-216 